\title{
Influence of Film Thickness and Heat Treatment on the Physical Properties of Mn Doped $\mathrm{Sb}_{2} \mathrm{Se}_{3}$ Nanocrystalline Thin Films
}

\author{
I. K. El Zawawi, Manal A. Mahdy, and E. A. El-Sayad \\ Solid State Physics Department, National Research Centre, Dokki, Giza 12622, Egypt \\ Correspondence should be addressed to Manal A. Mahdy; mams411@gmail.com
}

Received 28 November 2016; Revised 19 February 2017; Accepted 1 March 2017; Published 23 April 2017

Academic Editor: Meiyong Liao

Copyright (C) 2017 I. K. El Zawawi et al. This is an open access article distributed under the Creative Commons Attribution License, which permits unrestricted use, distribution, and reproduction in any medium, provided the original work is properly cited.

\begin{abstract}
Nanocrystalline thin films of $\mathrm{Sb}_{37.07} \mathrm{Mn}_{1.95} \mathrm{Se}_{60.98}$ with different thickness $(7,20,40$, and $80 \mathrm{~nm}$ ) were successfully prepared via inert gas condensation technique. As-deposited films showed amorphous structure by grazing incident in-plane X-ray diffraction (GIIXD) technique. All films of different thicknesses were heat treated at $433 \mathrm{~K}$ for $90 \mathrm{~min}$. The GIIXD pattern of annealed films showed nanocrystalline orthorhombic structure. The effect of thickness of annealed films on the structure and optical properties was studied. Calculated particle sizes are 20.67 and 24.15 for 40 and $80 \mathrm{~nm}$ thickness of heat treated film. High resolution transmission electron microscope HRTEM images and their diffraction patterns proved that $40 \mathrm{~nm}$ film thickness annealed at different temperature has nanocrystalline nature with observed (high) crystallinity that increases with annealing temperature. Blue shift of optical energy gap was observed from 1.68 to $2 \mathrm{eV}$ with decreasing film thickness from 80 to $7 \mathrm{~nm}$. Film thickness of $40 \mathrm{~nm}$ was exposed to different heat treated temperatures from 353 to $473 \mathrm{~K}$ to detect its effect on structure and optical and electrical properties. Blue shift from 1.73 to $1.9 \mathrm{eV}$ was observed in its optical band gap due to direct transition as heat treatment temperature decreasing from 473 to $353 \mathrm{~K}$. Electrical conductivity was studied for different heat treated films of thickness $40 \mathrm{~nm}$, and intrinsic conduction mechanism is dominant. The activation energy $E_{a}$ was affected by heat treatment process.
\end{abstract}

\section{Introduction}

Thin film technology is very important for many modern and promising technological applications, hence the emphasis on examining the surface science increasing the interest of physicists on account of its proven and many semiconductor devices applications like solar cells. Among these thin films, nanostructure thin films occupy large area in most modern applications because of its unique new properties that depend on the size quantization effect [1].

$\mathrm{V}_{2}-\mathrm{VI}_{3}$ semiconductor group attracts the attention of many scientists as a result of their physical properties that make them relevant in many applications [2]. Thin films of $\mathrm{Sb}_{2} \mathrm{~S}_{3}$ and $\mathrm{Sb}_{2} \mathrm{Se}_{3}$ specially have a great interest in switching, microwave, and optoelectronic applications [24]. $\mathrm{Sb}_{2} \mathrm{Se}_{3}$ is considered a promising candidate for verifying $>20 \%$ device efficiency as previously verified from theoretical calculations $[5,6]$. Antimony (Sb) and selenium (Se) are abundant and nontoxic elements that produced $\mathrm{Sb}_{2} \mathrm{Se}_{3}$ compound more suitable for photovoltaic application [7-9]. Nanostructure thin film of $\mathrm{Sb}_{2} \mathrm{Se}_{3}$ was previously discussed [10]. $\mathrm{Sb}_{2} \mathrm{Se}_{3}$ crystallized in orthorhombic structure and characterized by strong absorption coefficient $\left(>10^{-5} \mathrm{~cm}^{-1}\right)$ $[3,8]$.

Many researchers studied the effect of incorporation of $\mathrm{Mn}$ atoms on $\mathrm{V}_{2} \mathrm{VI}_{3}$ compounds [11-15]. In the earlier studies, chemical preparation methods such as solvothermal method [16-19], hydrothermal method [20-22], organometallic synthetic route [23], and microwave-assisted method [24] were used to synthesize $\mathrm{Sb}_{2} \mathrm{Se}_{3}$ nanomaterials.

In the present work, the synthesis of $\mathrm{Sb}_{1-x} \mathrm{Mn}_{x} \mathrm{Se}_{3}$ nanomaterial was demonstrated by inert gas condensation (IGC) as a physical method. Two effects were studied for the synthesized films. First, the effect of film thickness on the optical properties was discussed. Second, the effect of heat treatment on the structure and optical and electrical properties was demonstrated. 


\section{Experimental}

Thin films of $\mathrm{Sb}_{1-x} \mathrm{Mn}_{x} \mathrm{Se}_{3}$ of different thickness (7, 20, 40, and $80 \mathrm{~nm}$ ) have been synthesized via inert gas condensation (IGC) method on freshly cleaned glass substrates at $300 \mathrm{~K}$. Edward coating unit Model E-306 was used to synthesize thin films under background argon gas with pressure of $\sim 2 \times 10^{-3}$ Torr. Gold quartz crystal sensor was attached to thickness monitor (FTM5) used for recording the film thickness during deposition process. Heat treatment process was performed on different thickness of films at $433 \mathrm{~K}$ for $90 \mathrm{~min}$. Film of thickness $40 \mathrm{~nm}$ is exposed to heat treatment at different temperatures of $353,393,433$, and $473 \mathrm{~K}$ for $90 \mathrm{~min}$.

The quantitative chemical analysis of the thin film was determined using energy dispersive X-ray analysis (EDX) technique. The EDX unit connected with field emission scanning electron microscope.

Grazing incident in-plane X-ray diffraction (GIIXD) technique was used to examine the structure of thin films using Philips X'Pert diffractometer with CuK $\alpha$. High resolution transmission electron microscope (HRTEM) was used to inspect the micrographs and structure of films. The surface morphology of the thin films was inspected by field emission scanning electron microscope (FESEM) Model Quanta FEG 250, Czech Republic. Double beam spectrophotometer (Model JascoV-570) was used for recording transmission and reflection spectra of thin films in the spectral range from 190 to $2500 \mathrm{~nm}$ at room temperature.

The d.c. electrical conductivity of heat treated film of thickness $40 \mathrm{~nm}$ at different temperatures was measured in vacuum of $\sim 10^{-2}$ Torr at Pyrex cryostat. The resistance of thin films was recorded between two silver electrodes to ensure good ohmic contact using 6517B Keithley electrometer. The temperature of thin film was determined during experiment using $\mathrm{k}$-type thermocouple as a temperature sensor.

\section{Results and Discussion}

Thin films of different thickness of $\mathrm{Mn}$ doped $\mathrm{Sb}_{2} \mathrm{Se}_{3}$ (7, 20, 40 , and $80 \mathrm{~nm}$ ) were deposited by inert gas condensation (IGC) technique. The elemental chemical composition analysis of the successful deposited thin film of thickness $80 \mathrm{~nm}$ on stub of carbon was measured. The EDX results demonstrate that the thin film is composed of the elements $\mathrm{Sb}, \mathrm{Mn}$, and Se with the atomic ratios (at \%) of 37.07, 1.95, and 60.98 respectively. This confirms that the chemical composition of examined films is $\mathrm{Sb}_{37.07} \mathrm{Mn}_{1.95} \mathrm{Se}_{60.98}$ as derived from the EDX results.

The most effective way to understand the constituent of thin films is obtained through analyzing their structural, electrical, and optical properties. Therefore, the effect of both thickness of annealed films and annealing will be discussed on basis of their structural and physical behaviors.

The grazing incident in-plane X-ray diffraction (GIIXD) patterns of $\mathrm{Sb}_{37.07} \mathrm{Mn}_{1.95} \mathrm{Se}_{60.98}$ films of constant thickness $80 \mathrm{~nm}$ and different conditions of being as-deposited and heat treated at $433 \mathrm{~K}$ for $90 \mathrm{~min}$ at vacuum of $10^{-2}$ Torr were recorded in Figure 1. The X-ray pattern of as-deposited film showed amorphous structure due to the absence of any diffraction peaks as seen in Figure 1(a). Otherwise, definite diffraction peaks are observed in X-ray pattern for heat treated film (Figure 1(b)). These diffraction peaks indicated crystallization with orthorhombic structure according to the $\mathrm{X}$-ray international card (number 15-0861) [25]. This result is in agreement with that recorded previously by other authors $[10,18,26]$. Since EDX results proved the presence of $\mathrm{Mn}$ dopant with 1.95 at \%, Sb has a deficiency in its atomic percent from $\mathrm{Sb}_{2} \mathrm{Se}_{3}$ compound. Also, no diffraction peaks appeared in the X-ray pattern for Mn element. So, it is expected that Mn introduced substitutionally with the Sb element in the lattice of $\mathrm{Sb}_{2} \mathrm{Se}_{3}$ compound as a result of $\mathrm{Mn}$ dopant has a slightly smaller ionic radius $(0.58 \AA)$ than that of $\mathrm{Sb}(0.76 \AA)$ [27]. This substitutional introducing of $\mathrm{Mn}$ with $\mathrm{Sb}$ element has been proved in our previous work [28], which showed that the unit cell volume of $\mathrm{Sb}_{35.75} \mathrm{Mn}_{1.43} \mathrm{Se}_{62.82}$ polycrystalline powder is slightly smaller than that of $\mathrm{Sb}_{2} \mathrm{Se}_{3}$ compound. The crystallite size was calculated from the X-ray peak with orientation (230) according to Scherrer formula as follows $[29,30]$ :

$$
D=\frac{k \lambda}{\beta \cos (\theta)},
$$

where $D$ is the crystallite or particle size, $\lambda$ is the $\mathrm{X}$ ray wavelength, $k$ represents the particle shape factor, and $\beta$ represents the peak full width at half maximum. The estimated particle size of heat treatment film $(80 \mathrm{~nm})$ is about $24.15 \mathrm{~nm}$. This range indicated that the film crystallizes due to being heat treated at $433 \mathrm{~K}$ for $90 \mathrm{~min}$ at nanocrystalline orthorhombic structure.

Thin film of thickness $40 \mathrm{~nm}$ was annealed at different temperatures and the effect of annealing temperature was studied on its structure.

Figure 2 shows GIIXD patterns of thin film $(40 \mathrm{~nm})$ annealed at $353,393,433$, and $473 \mathrm{~K}$ for $90 \mathrm{~min}$. The $\mathrm{X}$ ray patterns for thin film after being heat treated at $353 \mathrm{~K}$ (Figure 2(a)) showed very low crystallinity with the absence of sharp X-ray peaks, whereas high resolution transmission electron microscopy (HRTEM) examination for the same heat treated film at $353 \mathrm{~K}$, resulting in diffraction pattern that showed some definite rings as illustrated in the inset diffraction pattern in Figure 2(a). These definite rings indicate the presence of crystalline nature for the examined heat treated film at $353 \mathrm{~K}$. This emphasizes that the HRTEM could give more information for examining the structure of thin films with low thickness.

On the other side, for the GIIXD studies, the crystallinity starts to appear after thin film was heat treated at $393 \mathrm{~K}$ as illustrated in Figure 2(b). This crystallinity is represented by appearance of some small diffraction lines which crystallized in a single phase of an orthorhombic structure with planes of orientation (120), (130), (230), (240), (530), and (061), while after heat treatment at higher temperatures 433 and $473 \mathrm{~K}$ (Figure 2(c, d)), the crystallization increases by appearance of more diffraction lines with higher intensities than those illustrated for heat treated film at $393 \mathrm{~K}$. The insets of HRTEM diffraction pattern for heat treated films at 393, 433, and 


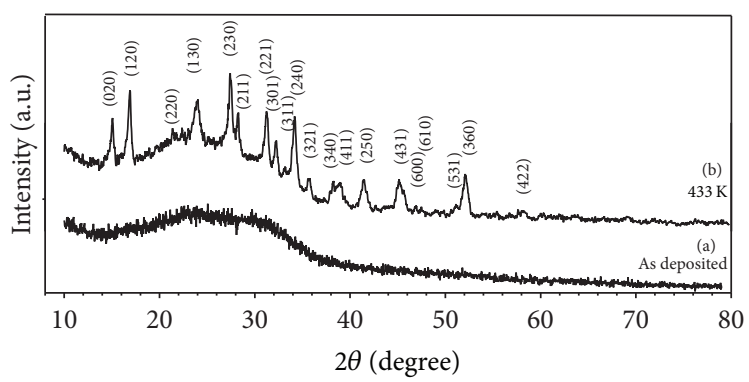

FIgURE 1: GIIXD pattern of $\mathrm{Sb}_{37.07} \mathrm{Mn}_{1.95} \mathrm{Se}_{60.98}$ film of $80 \mathrm{~nm}$ thickness (a) as-deposited and (b) annealed at $433 \mathrm{~K}$ for $90 \mathrm{~min}$.

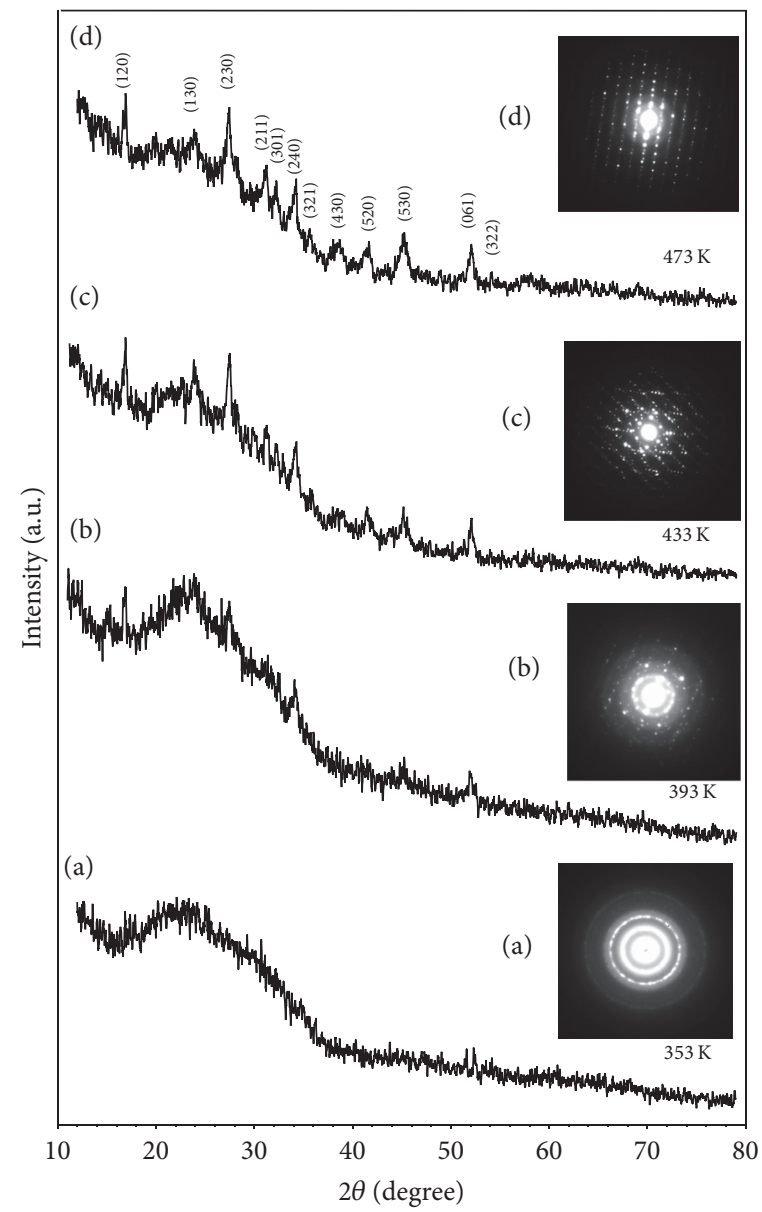

FIgURE 2: GIIXD patterns of $\mathrm{Sb}_{37.07} \mathrm{Mn}_{1.95} \mathrm{Se}_{60.98}$ film of $40 \mathrm{~nm}$ thickness with different annealing temperature and the inset HRTEM diffraction patterns: (a) $353 \mathrm{~K}$, (b) $393 \mathrm{~K}$, (c) $433 \mathrm{~K}$, and (d) $473 \mathrm{~K}$.

$473 \mathrm{~K}$ shown in Figure 2(b, c, d), respectively, confirm the increase in crystallinity of the studied films with increasing the annealing temperature.

From Figure 2, it is concluded that the crystallinity of $40 \mathrm{~nm}$ film thickness improved with rising annealing temperature, resulting in the degree of crystallinity dependence on the heating temperatures during annealing process. The broadening in X-ray peaks appears to be due to the nanocrystalline structure in the heat treated films. From the width of X-ray peak with orientation line (230), the crystallite size can be estimated according to (1). The calculated crystallite sizes for $40 \mathrm{~nm}$ film thickness heat treated at 433 and $473 \mathrm{~K}$ from peak orientation of (230) are 20.67 and $21.41 \mathrm{~nm}$. The crystallite size from GIIXD pattern for heat treated film at $393 \mathrm{~K}$ is not accurately calculated due to the lower intensity of the representative line (230).

The micrograph images with different magnifications of HRTEM for film thickness $40 \mathrm{~nm}$ exposed to heat treatment 


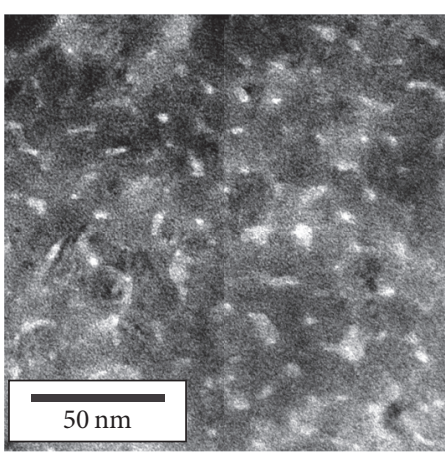

(a)

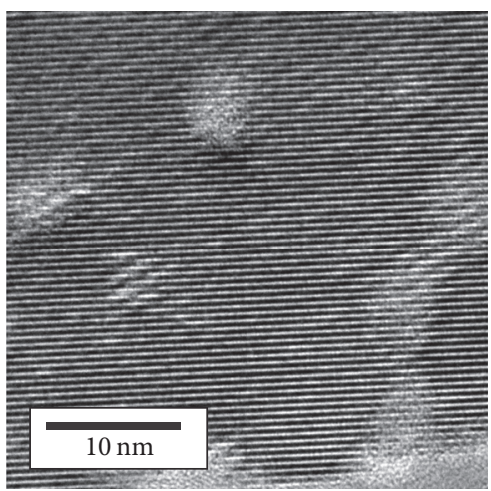

(d)

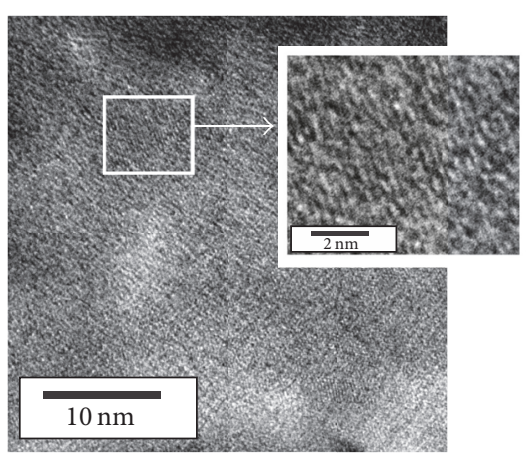

(b)

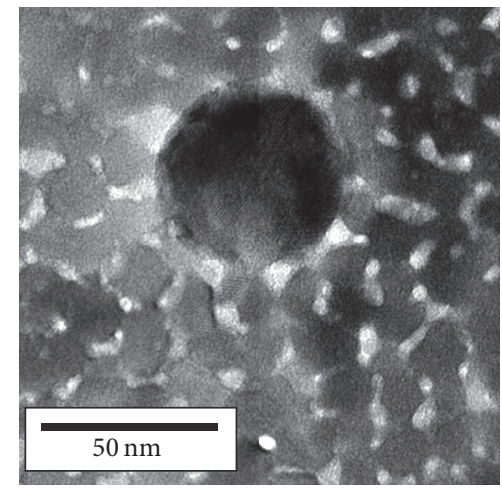

(e)

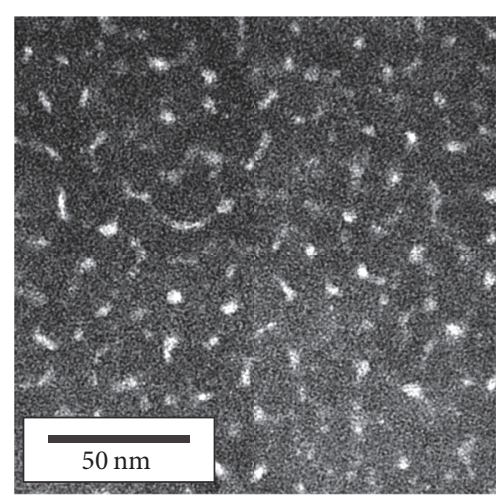

(c)

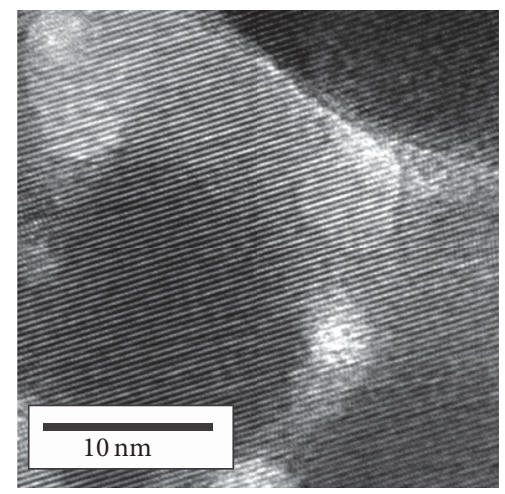

(f)

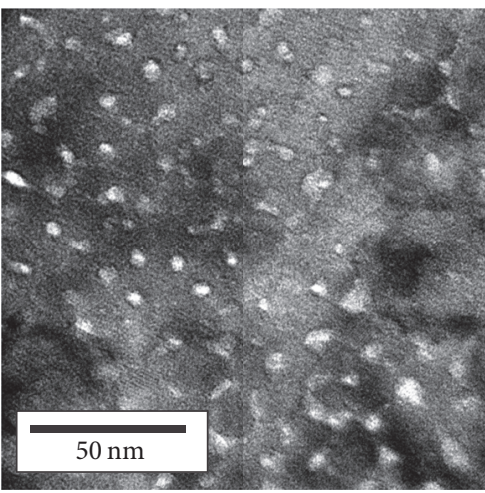

(g)

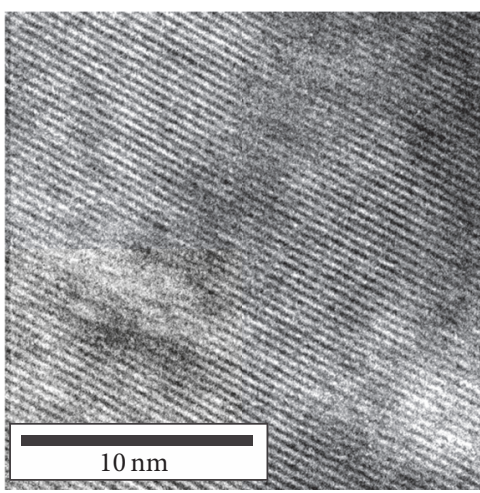

(h)

Figure 3: HRTEM images for $40 \mathrm{~nm}$ film thickness after exposure to different annealing temperatures (a, b) $353 \mathrm{~K}$, (c, d) $393 \mathrm{~K}$, (e, f) $433 \mathrm{~K}$, and $(\mathrm{g}, \mathrm{h}) 473 \mathrm{~K}$.

process at different annealing temperatures from 353 to $473 \mathrm{~K}$ are illustrated in Figure 3. Figures 3(a), 3(c), 3(e), and 3(g) demonstrate the micrograph images at magnification scale $50 \mathrm{~nm}$ that shows the nanoparticle of the annealed film at different annealing temperatures. In the other side, Figures 3(b), 3(d), 3(f), and 3(h) illustrate the long-range order for periodicity of lattice which proved the high crystallinity of annealed films as explained with X-ray patterns and HRTEM diffraction patterns in Figure 2. Also, it is observed that the crystallinity depends on the annealing temperature; that is, it increases with rising annealing temperature.
The surface morphology of $40 \mathrm{~nm}$ film thickness annealed at different temperature has been examined by field emission scanning electron microscope (FESEM) as illustrated in Figure 4. The heat treated films showed a smooth homogenous surface and the appearance of some aggregates has been realized in Figure 4(d) than other films, indicating some nanoparticle aggregation due to the effect of high annealing temperature at $473 \mathrm{~K}$.

Transmission $\mathscr{T}$ and reflection $R$ spectra of $\mathrm{Sb}_{37.07} \mathrm{Mn}_{1.95} \mathrm{Se}_{60.98}$ thin film with different thicknesses after annealing at $433 \mathrm{~K}$ were illustrated in Figure 5. It 


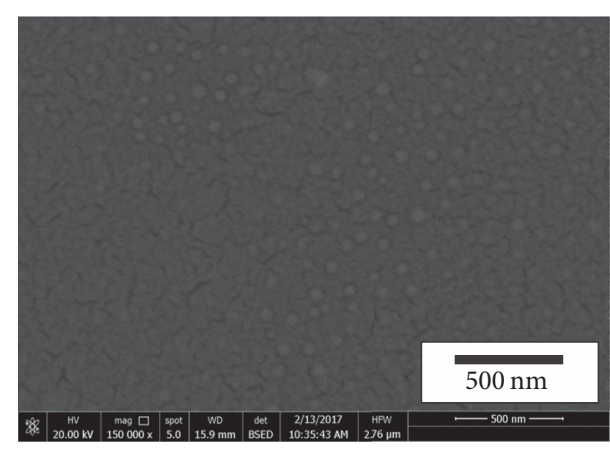

(a)

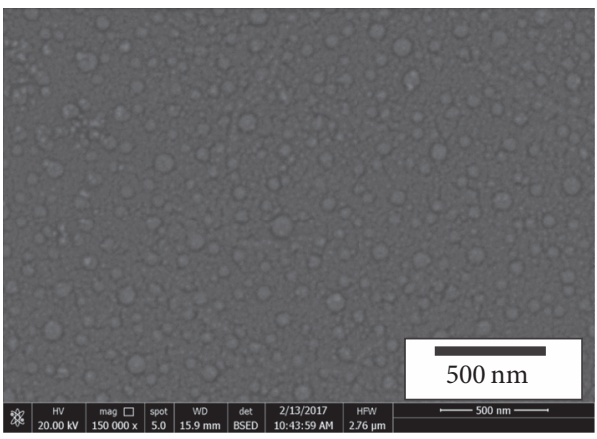

(c)

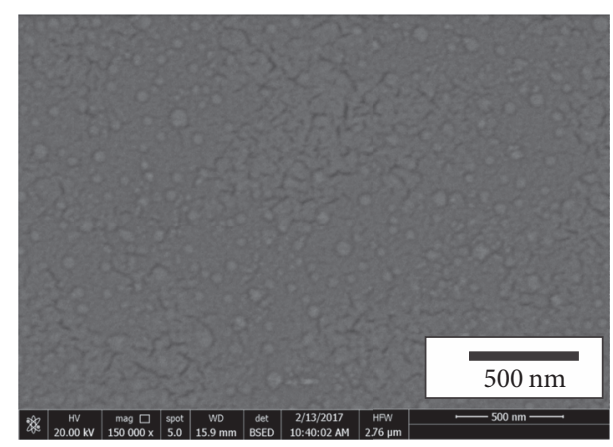

(b)

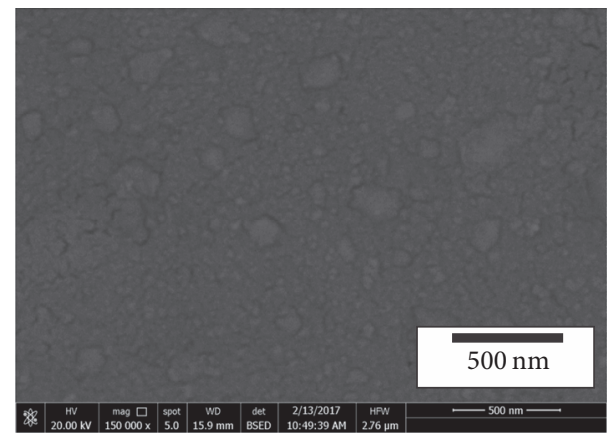

(d)

Figure 4: FESEM images of $\mathrm{Sb}_{37.07} \mathrm{Mn}_{1.95} \mathrm{Se}_{60.98}$ film of $40 \mathrm{~nm}$ thickness with different annealing temperatures (a) $353 \mathrm{~K}$, (b) $393 \mathrm{~K}$, (c) $433 \mathrm{~K}$, and (d) $473 \mathrm{~K}$.

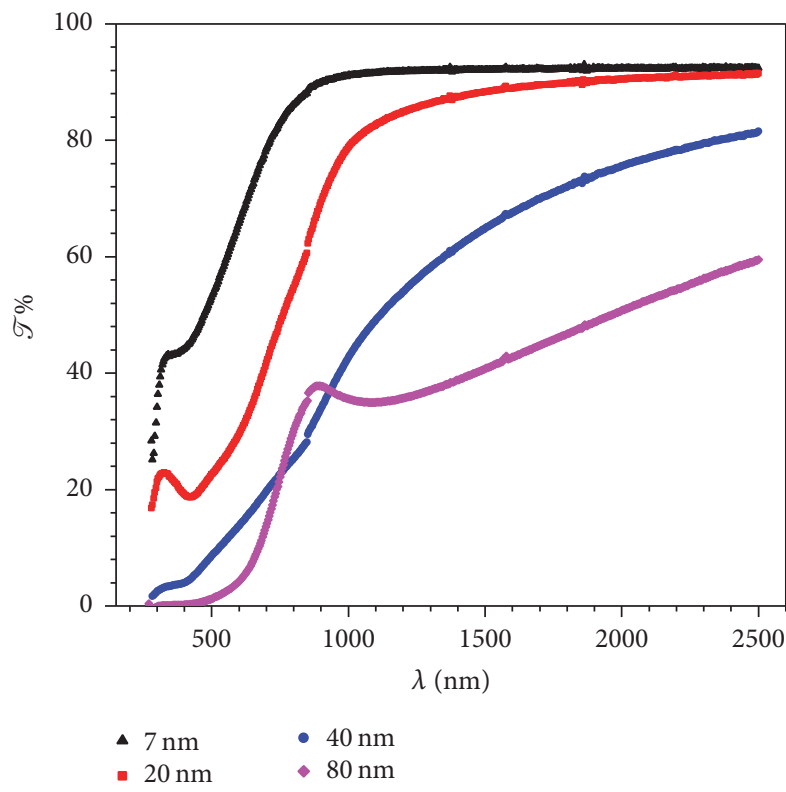

(a)

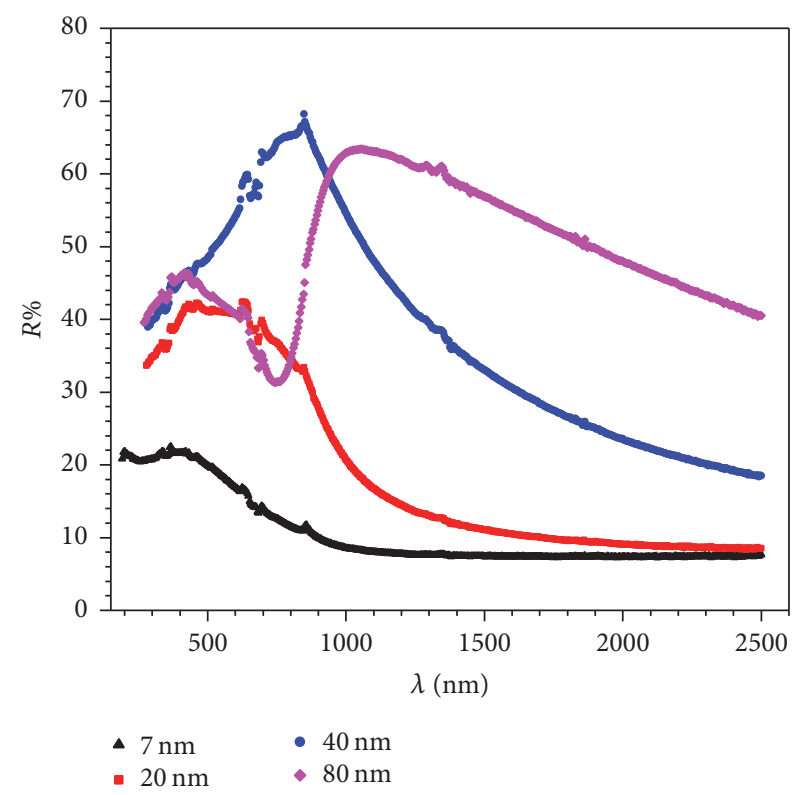

(b)

Figure 5: Transmission $\mathscr{T}$ and reflection $R$ spectra as a function of wavelength for $\mathrm{Sb}_{37.07} \mathrm{Mn}_{1.95} \mathrm{Se}_{60.98}$ film with different thickness.

is obvious that the values of $\mathscr{T}$ and $R$ depend on film thickness. As observed, $\mathscr{T}$ values increase with decreasing film thickness, while $R$ values rise with increasing film thickness as depicted in Figure 5(b).
The study of the absorption coefficient $\alpha$ spectra in the region near the fundamental edge provides important information around interband transitions and optical band gap structure of the materials. The absorption coefficient $\alpha$ 


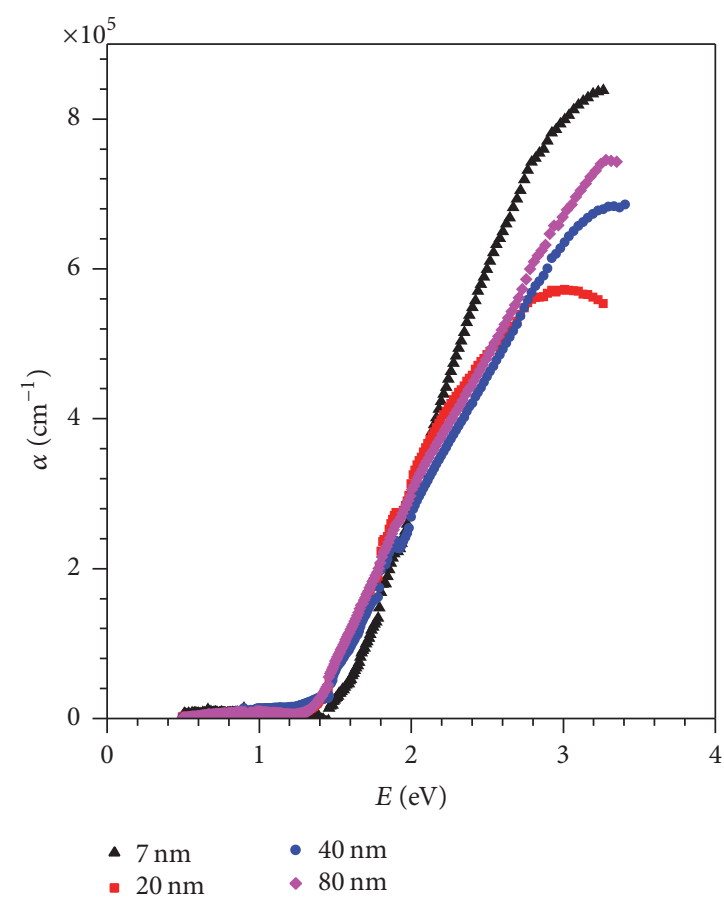

FIgURE 6: Absorption coefficient as a function of photon energy for $\mathrm{Sb}_{37.07} \mathrm{Mn}_{1.95} \mathrm{Se}_{60.98}$ film with different thickness.

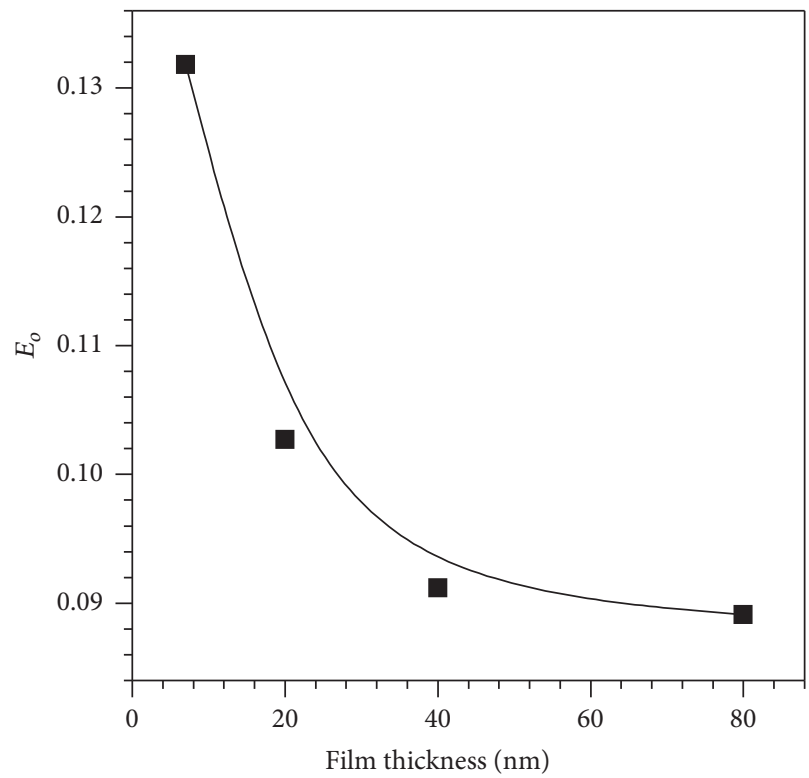

Figure 7: Band tail width $E_{o}$ as a function of film thickness for $\mathrm{Sb}_{37.07} \mathrm{Mn}_{1.95} \mathrm{Se}_{60.98}$ thin films.

spectra of the prepared annealed films were calculated from transmission and reflection spectra [31]. The calculated $\alpha$ values as a function of photon energy are shown in Figure 6. It is observable from Figure 6 that all the films under investigation have high absorption behavior lying in region of $\geq 10^{5} \mathrm{~cm}^{-1}$.

At energies lower than the band edge, the band tail width, $E_{o}$, can be estimated from the slope of straight portion in the plot $\ln (\alpha)$ versus photon energy [32]. In this region, the absorption coefficient obeys an exponential behavior according to the following Urbach rule [33]:

$$
\alpha=\alpha_{o} \exp \left(\frac{h \nu}{E_{o}}\right)
$$

where $E_{o}$ is the band tail width which characterized the localized defect states, $\alpha_{o}$ is a preexponential factor. The band tail width described the degree of disordered in the localized states of the deposited films. The values of $E_{o}$ are compiled in Table 1 and cleared as seen in Figure 7. It is revealed 

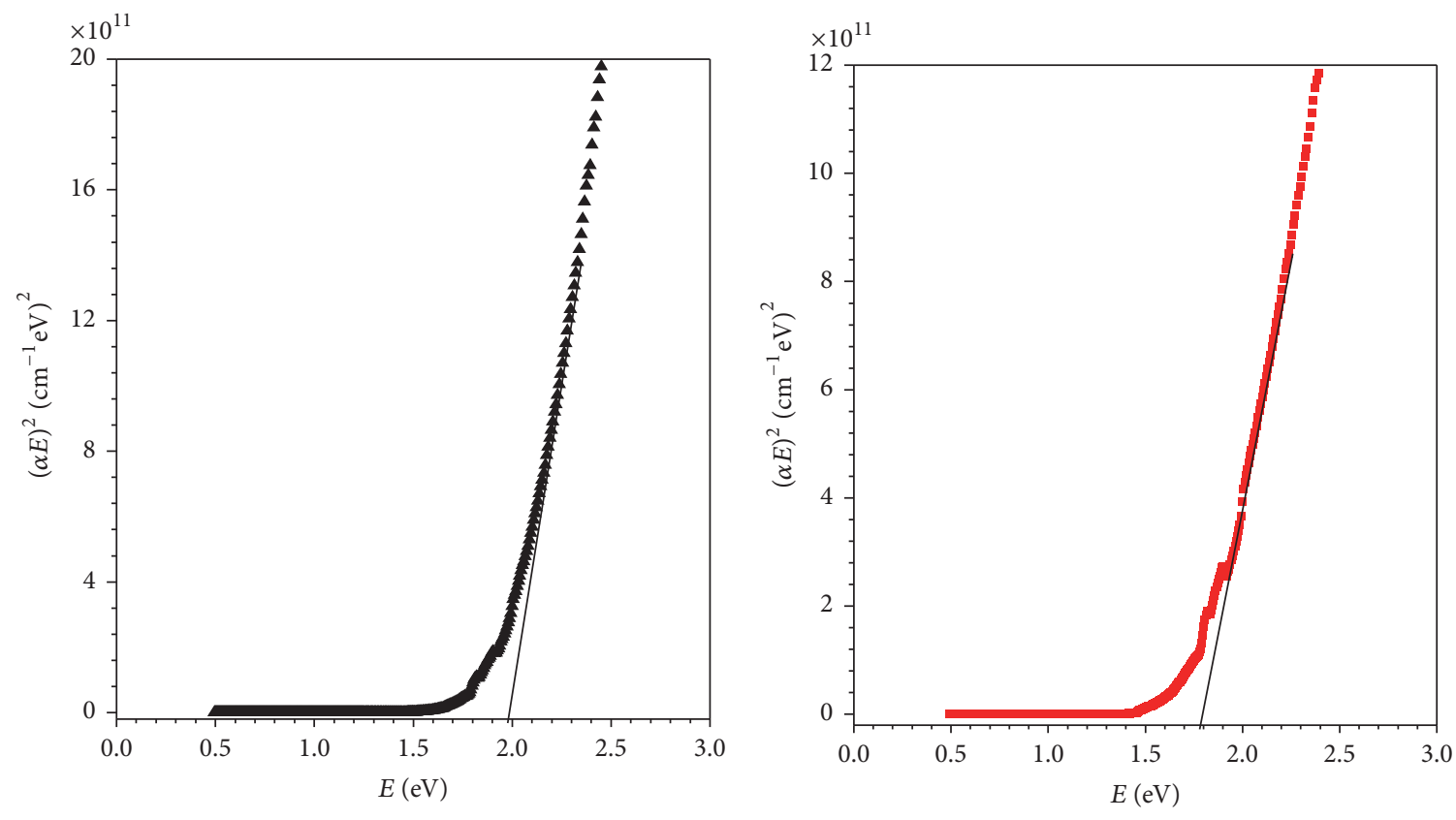

A $7 \mathrm{~nm}$

(a)

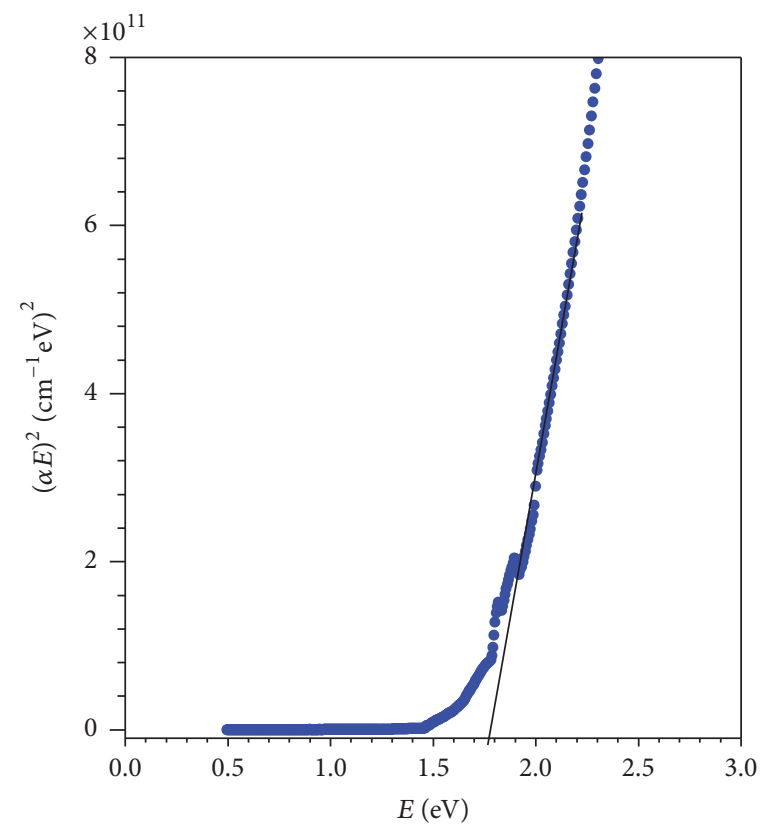

- $40 \mathrm{~nm}$

- $20 \mathrm{~nm}$

(b)

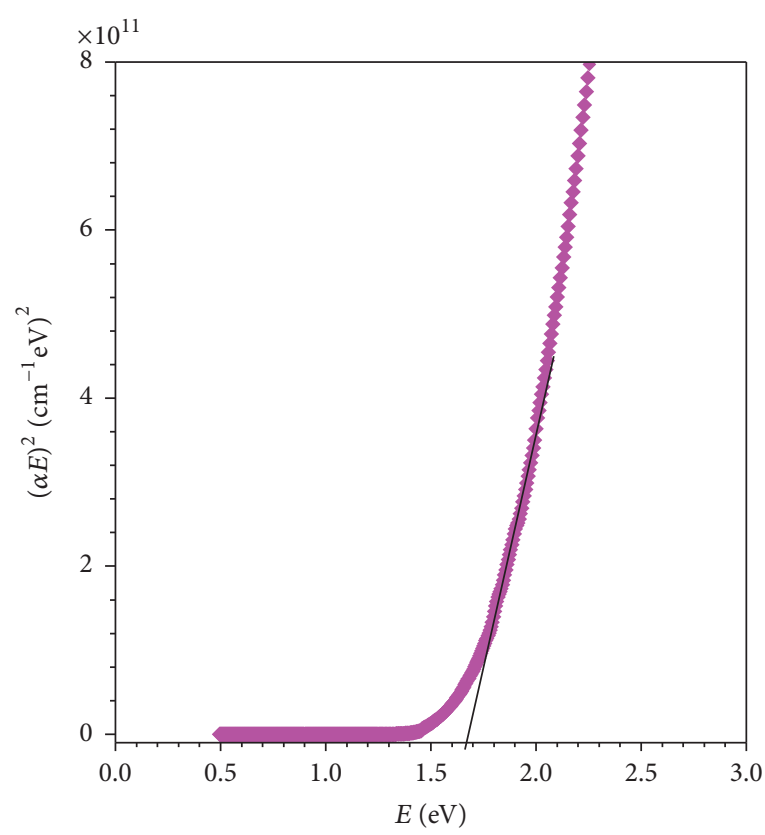

- $80 \mathrm{~nm}$

(c)

(d)

Figure 8: $(\alpha E)^{2}$ versus $E$ plots for $\mathrm{Sb}_{37.07} \mathrm{Mn}_{1.95} \mathrm{Se}_{60.98}$ thin film with different thickness.

that the values of band tail width decrease with increasing film thickness. This means that degree of disordered in representative films decreases as the film thickness rises [34].

Optical band gap energy $E_{g}$ can be estimated from the Tauc relation $[31,35]$.

$$
\alpha h v=\beta\left(h v-E_{g}\right)^{r},
$$

where $\beta$ is a constant, $v$ is the wavelength frequency, $h$ represent Planck's constant, and $r$ is the exponent which refers to the nature of the band transition, $r=1 / 2$ and 2 corresponds to direct and indirect allowed transitions. The values of band gap can be calculated from extrapolation of the best fit lines of the plots of $(\alpha h v)^{2}$ against photon energy $(E=h v)$ as drawn in Figure 8. It is clear that the best linear 


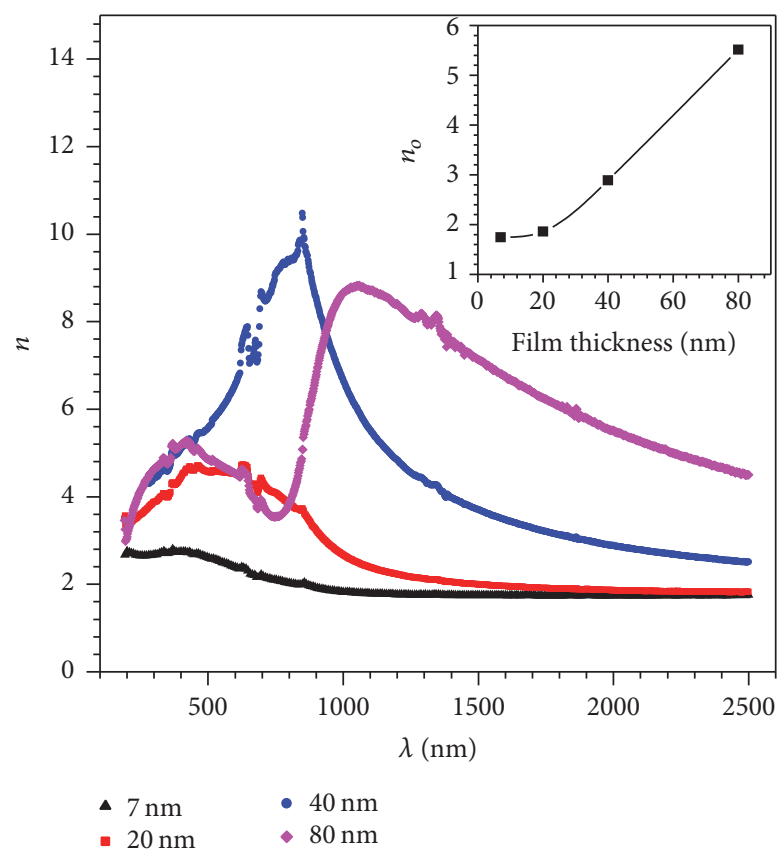

Figure 9: Refractive index $n$ of $\mathrm{Sb}_{37.07} \mathrm{Mn}_{1.95} \mathrm{Se}_{60.98}$ thin film of different thickness as function of wavelength. The inset figure represents variation of refractive index $n_{o}$ at $2000 \mathrm{~nm}$ wavelength with film thickness.

TABLE 1: Particle size and optical parameters of $\mathrm{Sb}_{37.07} \mathrm{Mn}_{1.95} \mathrm{Se}_{60.98}$ thin film with different thickness after being heat treated at $433 \mathrm{~K}$ for $90 \mathrm{~min}$.

\begin{tabular}{lcccc}
\hline Film thickness $(\mathrm{nm})$ & $D(\mathrm{~nm})$ & $E_{g}(\mathrm{eV})$ & $E_{o}(\mathrm{eV})$ & 0.132 \\
\hline 7 & - & 2.00 & 0.103 & $\alpha_{o}\left(\mathrm{~cm}^{-1}\right)$ \\
20 & - & 1.80 & 0.091 & 135.8 \\
40 & 20.67 & 1.76 & 0.089 & 80.9 \\
80 & 24.15 & 1.68 & 36.6 \\
\hline
\end{tabular}

fit is obtained for $r=1 / 2$, which refers to direct allowed transition for all heat treated films with thickness from 7 to $80 \mathrm{~nm}$. The band gap values ranging from 2.00 to $1.68 \mathrm{eV}$ for film thickness increased from 7 to $80 \mathrm{~nm}$. The obtained value $(2 \mathrm{eV})$ of $E_{g}$ is close to the previously reported results [36] and that reported for thin films of $\mathrm{Sb}_{2} \mathrm{Se}_{3}$ prepared via spray pyrolysis technique [37]. Table 1 showed that the band gap was affected by the film thickness, it decreases with rising film thickness, and it is larger than that corresponding to the bulk material of $\mathrm{Sb}_{2} \mathrm{Se}_{3}$ which is about $1 \mathrm{eV}$ [36].

The spectral variations of the calculated refractive index $n$ of the investigated heat treatment thin films with different thicknesses were illustrated in Figure 9. The refractive index increases with increasing film thickness in wavelength spectral range from 1000 to $2500 \mathrm{~nm}$. The inset figure illustrates the variation of refractive index $n_{0}$ with film thickness at wavelength $2000 \mathrm{~nm}$. It is noted that $n_{o}$ values increased exponentially from 1.74 to 5.51 as the film thickness increases from 7 to $80 \mathrm{~nm}$.

It is clear from Table 1 that as film thickness increases the particle size $D$ increases and both energy gaps $E_{g}$ and $E_{o}$ decrease.
The effect of annealing temperature was studied on the optical and electrical properties of $40 \mathrm{~nm}$ film thickness to detect the effect of the crystallinity on film behaviors.

Transmission $\mathscr{T}$ and reflection $R$ spectra for $40 \mathrm{~nm}$ film thickness of $\mathrm{Sb}_{37.07} \mathrm{Mn}_{1.95} \mathrm{Se}_{60.98}$ after being annealed at different temperatures were depicted in Figure 10. The dependence of transmission and reflection values on heat treatment process are observed, resulting in values decreasing as the heat treated temperature increases, while $R$ values increase with temperature of heat treatment process. The increment of heat treated temperature leads to imperfection decrement in films under investigation. This result is due to crystallinity increasing after performing heat treatment process as proved by GIIXD patterns (Figure 2). The increase in film crystallinity with rising of annealing temperature agrees with that reported at previous results [38].

The calculated absorption coefficient $\alpha$ as a function of photon energy $E$ for $40 \mathrm{~nm}$ film thickness after heat treated at different temperature was illustrated in Figure 11. The films have high absorption coefficient values of about $10^{5} \mathrm{~cm}^{-1}$ that represent strong absorption values.

According to (3), optical band gap $E_{g}$ was estimated from the extrapolation of linear part of the curves in Figure 12, and 


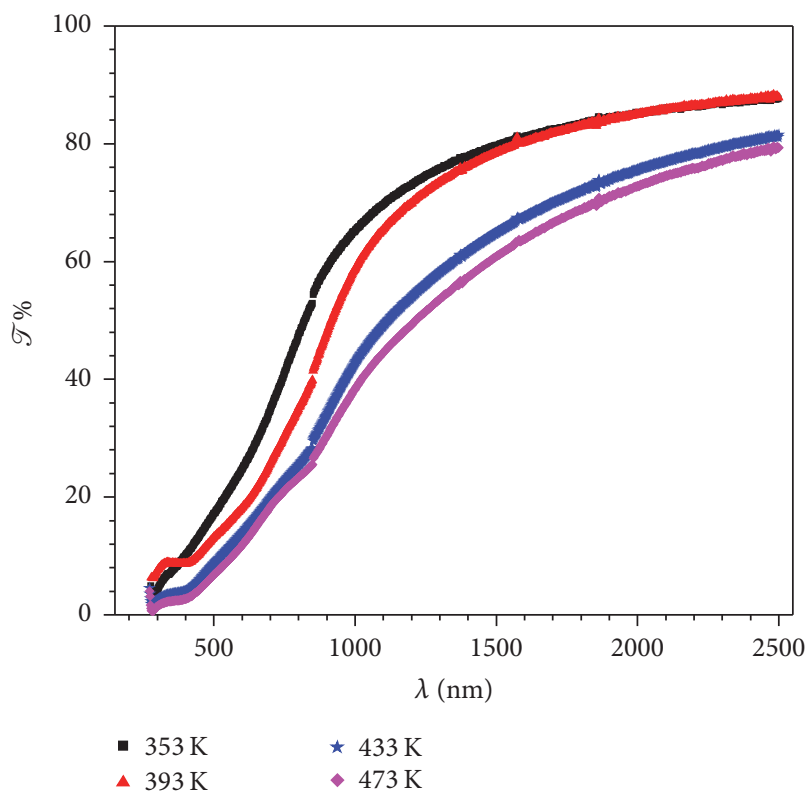

(a)

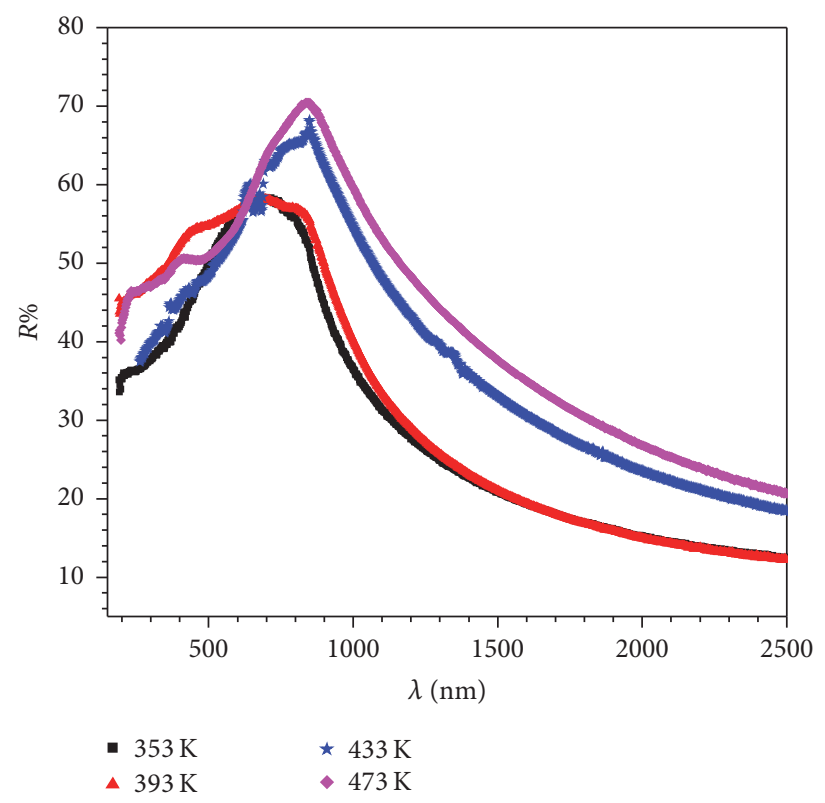

(b)

FIGURE 10: Transmission $\mathscr{T}$ and reflection $R$ spectra as a function of wavelength for $40 \mathrm{~nm}$ film thickness with different annealing temperature.

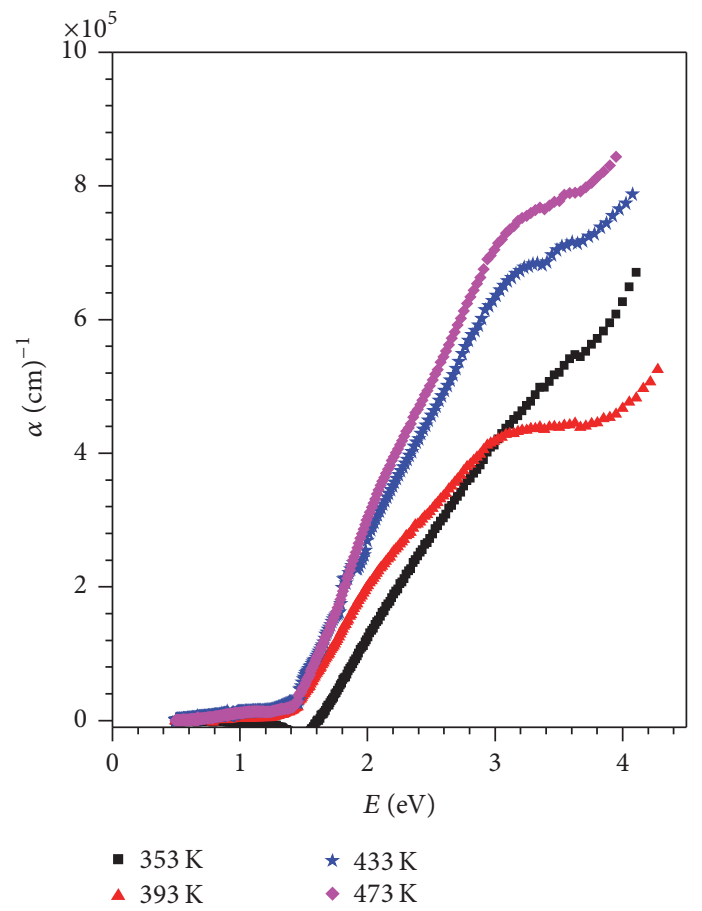

FIGURE 11: Absorption coefficient spectra for $40 \mathrm{~nm}$ film thickness with different annealing temperature.

the best linear fit was observed for exponent $r=1 / 2$ (direct allowed transition). The estimated $E_{g}$ values were collected in Table 2; it is observable that the $E_{g}$ values decrease with increasing heat treated temperature which influence the crystallinity of the thin films. On the other hand, the refractive index $n$ of heat treated thin films from 353 to $473 \mathrm{~K}$ was shown in Figure 13. The calculated values of refractive index $n_{o}$ at $2000 \mathrm{~nm}$ were inset in Figure 13; it increases with heat treatment as a result of improving crystallinity.

Conductivity is an important property, which gives more reliable information about the transport phenomena and other physical properties of the materials. 


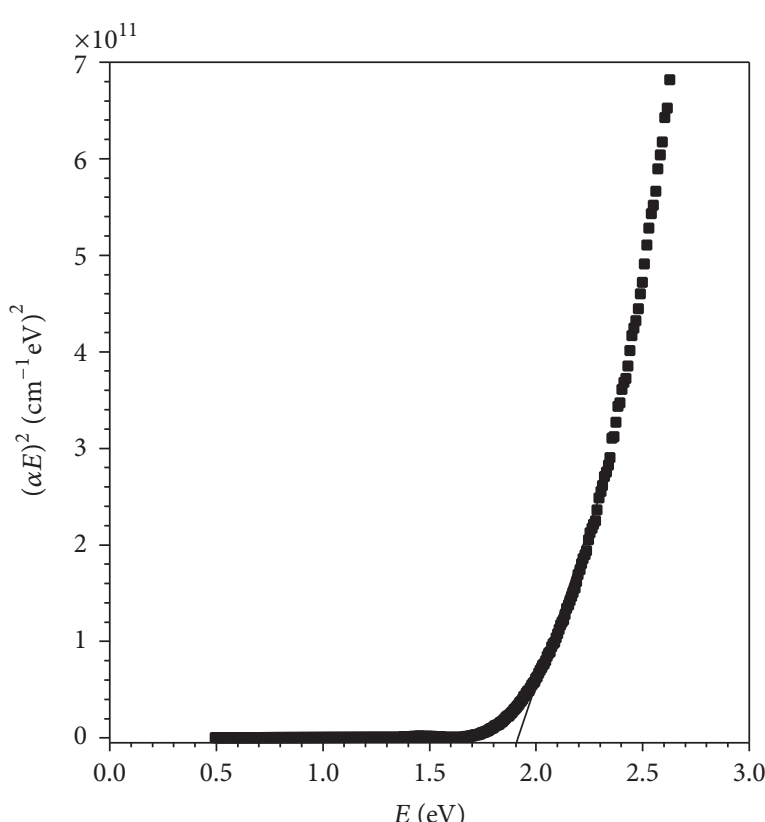

- $353 \mathrm{~K}$

(a)

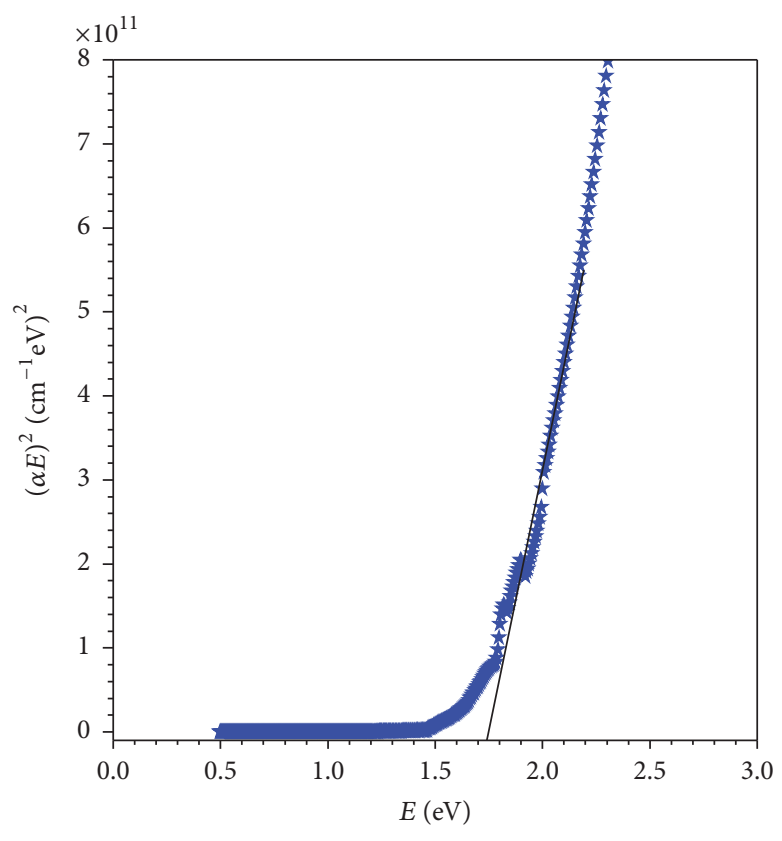

$\star 433 \mathrm{~K}$

(c)

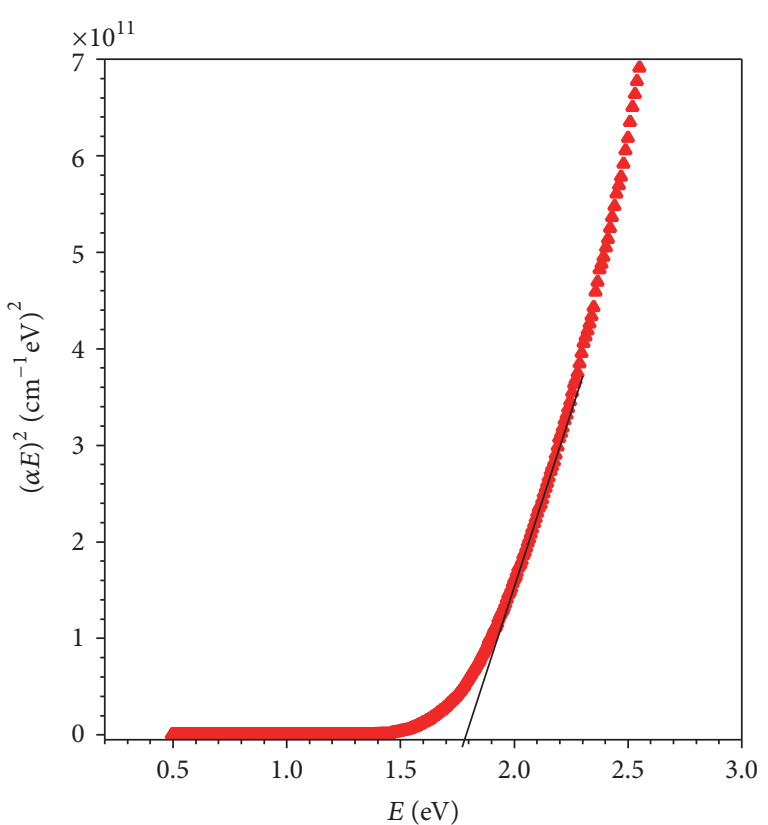

- $393 \mathrm{~K}$

(b)

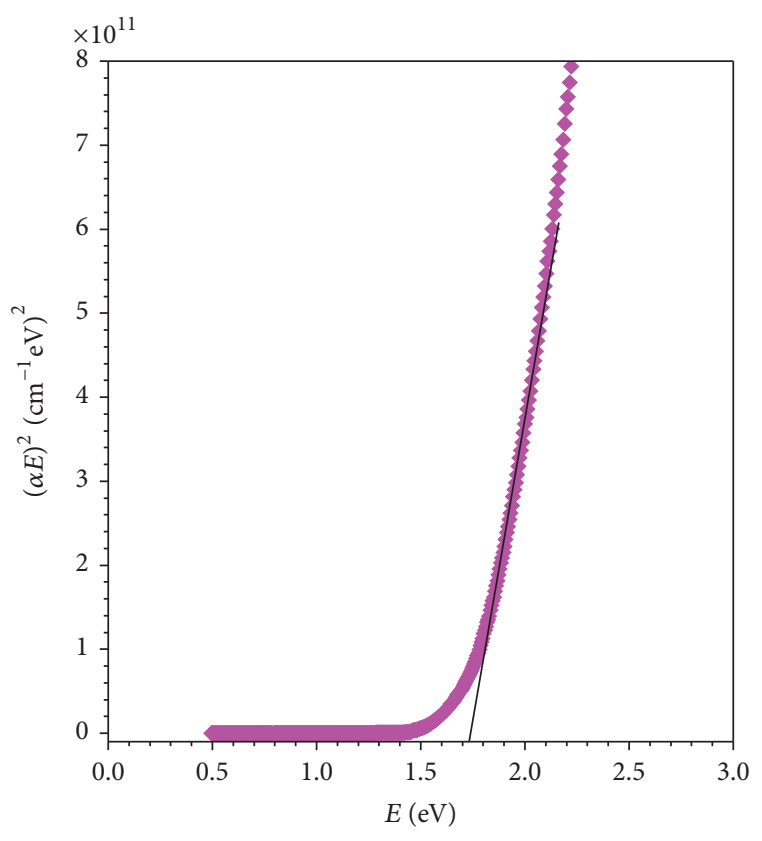

- $473 \mathrm{~K}$

(d)

FIGURE 12: $(\alpha E)^{2}$ versus $E$ plots for $40 \mathrm{~nm}$ film thickness with different annealing temperature.

TABLE 2: Calculated values of particle size $D$, optical band gap $E_{g}$, activation energy $E_{a}$, and preexponential factor $\sigma_{o}$ for $40 \mathrm{~nm}$ film thickness annealed at different temperatures $T(\mathrm{~K})$.

\begin{tabular}{lcccc}
\hline$T(\mathrm{~K})$ & $D(\mathrm{~nm})$ & $E_{g}(\mathrm{eV})$ & $E_{a}(\mathrm{eV})$ & $\sigma_{o}(\Omega \cdot \mathrm{m})^{-1}$ \\
\hline 353 & - & 1.90 & 0.978 & $4.60 \times 10^{10}$ \\
393 & - & 1.79 & 0.809 & $9.97 \times 10^{8}$ \\
433 & 20.67 & 1.76 & 0.765 & $2.77 \times 10^{8}$ \\
473 & 21.41 & 1.73 & 0.768 & $1.92 \times 10^{8}$ \\
\hline
\end{tabular}




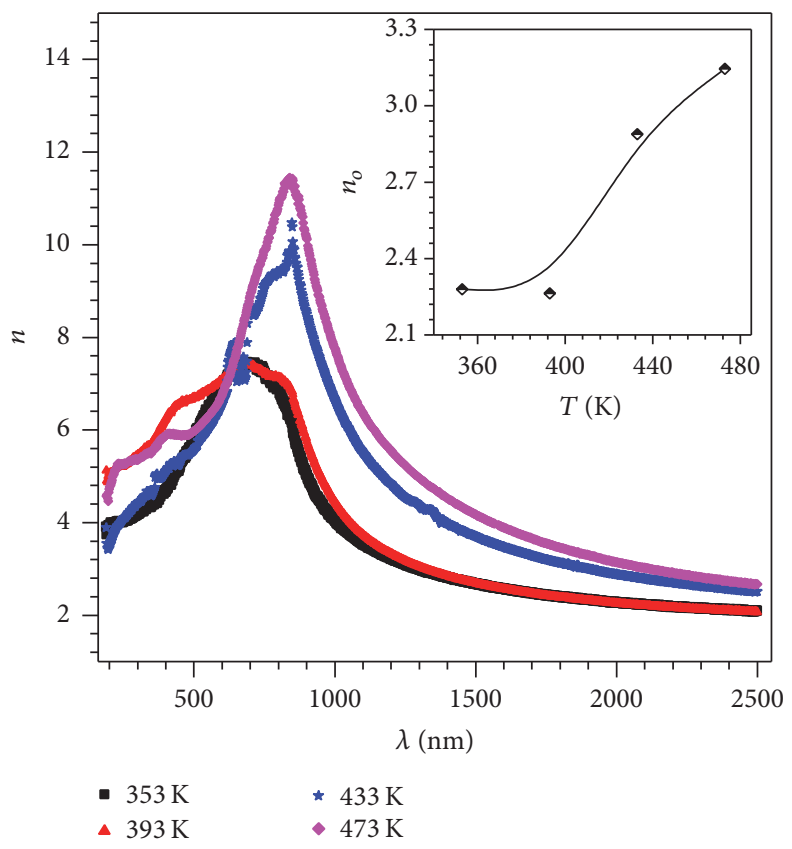

FigURE 13: Refractive index of $40 \mathrm{~nm}$ film thickness of different annealing temperature. The inset figure represents variation of refractive index at $2000 \mathrm{~nm}$ wavelength with annealing temperatures.

Electrical conductivity at temperature $T$ is given by the following relation $[39,40]$ :

$$
\sigma(T)=\sigma_{o} \exp \left(-\frac{E_{a}}{k_{B} T}\right)
$$

where $k_{B}$ is a Boltzmann constant, $\sigma_{o}$ is a preexponential factor, and $E_{a}$ represents the material activation energy.

The variation of resistivity with temperature was recorded for all annealed films of $40 \mathrm{~nm}$ thickness. The calculated d.c. conductivity $\sigma$ versus temperature $T$ was depicted in Figure 14. The electrical conductivity increases with temperature, which indicates the semiconductor behavior of materials [41]. It is obvious from Figure 14 that conductivity has a rapid variation with temperature in the whole temperature range. This means that the current density increases due to the thermal activated process. The linear behavior of $\ln (\sigma)$ with reciprocal of temperature $T$ for all films indicates that conduction is through the process of thermal activation. The electrical conductivity for all measured films indicates straight lines with one slope, which refers to one type of conduction mechanism.

The activation energy $E_{a}$ of thin films can be calculated from the slope of the straight lines (Figure 14) and the preexponential factor $\sigma_{o}$ calculated from the intersection of these straight lines with the ordinate axis. The calculated values of $E_{a}$ and $\sigma_{o}$ are assembled in Table 2. These values of $E_{a}$ are probably due to the Fermi level shift, and it was found to be nearly equal to half of the obtained optical band gap, indicating that the intrinsic conduction mechanism in measured heat treated thin films of $40 \mathrm{~nm}$ thickness is dominant $[39,42]$. The intrinsic mechanism in semiconductor materials is due to the carrier mobility. It could be concluded that the heat treatment temperature does not influence the conduction mechanism of the investigated films. Moreover, the activation energy $E_{a}$ was found to vary with the heat treatment temperature as shown in Figure 15. Calculated $E_{a}$ decreases rapidly with increasing heat treated temperature from 353 to $393 \mathrm{~K}$ and is approximately constant with higher temperature of 433 and $473 \mathrm{~K}$. The preexponential factor $\sigma_{o}$ depends on the temperature of heat treatment process; it decreases with increasing heat treatment temperature.

From Table 2, it could be noticed that rising in temperature of heat treatment at constant heating time results in an increase in particle size which reflects decreasing in other optical and electrical parameters as $E_{g}, E_{a}$, and $\sigma_{o}$.

\section{Conclusion}

$\mathrm{Sb}_{37.07} \mathrm{Mn}_{1.95} \mathrm{Se}_{60.98}$ nanostructure thin film was physically synthesized with inert gas condensation method. Several thicknesses 7, 20,40, and $80 \mathrm{~nm}$ were deposited on glass substrates and then heat treated for $90 \mathrm{~min}$ at $433 \mathrm{~K}$. Film thickness effect on structure and optical properties was examined. Optical band gap was shifted to higher energy (blue shift) with decreasing film thickness. Film thickness of $40 \mathrm{~nm}$ was exposed to different annealing temperature ranging from 353 to $473 \mathrm{~K}$. Structure was affected by annealing temperature and blue shift in optical properties is observed with rising temperature. The long-range order of lattice periodicity was cleared in the HRTEM results 


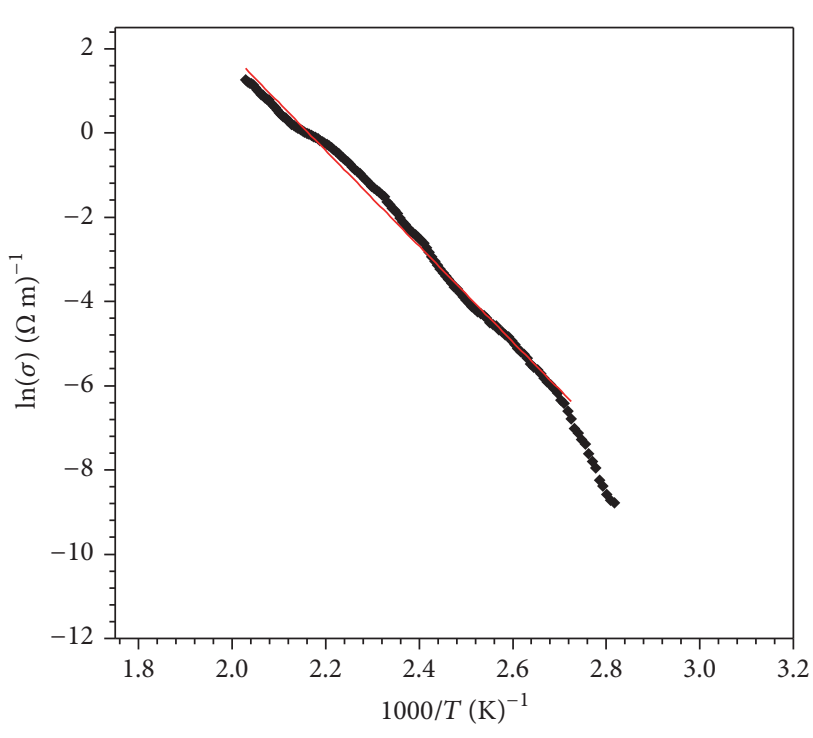

- $353 \mathrm{~K}$

(a)

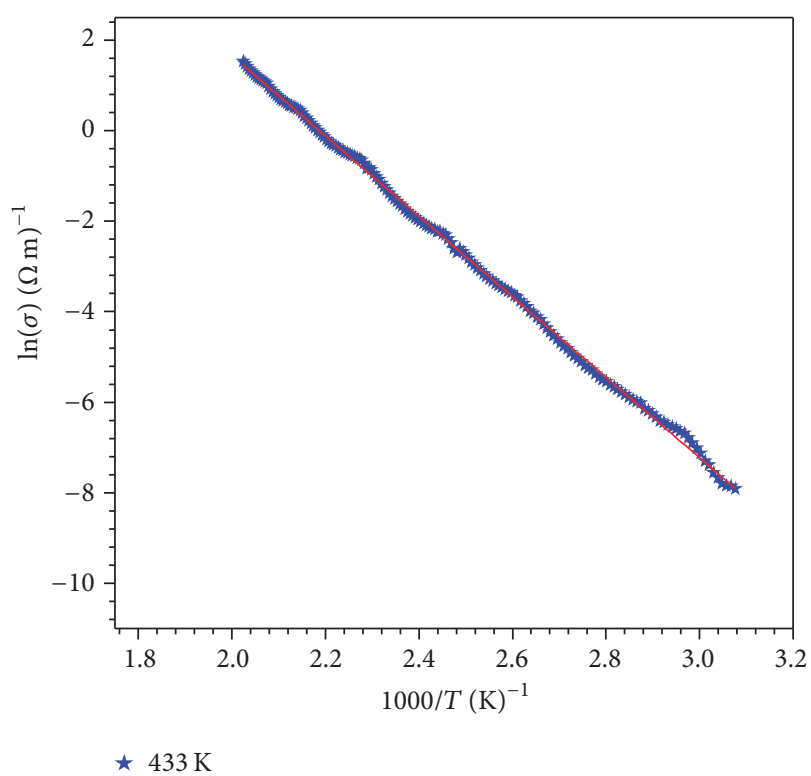

(c)

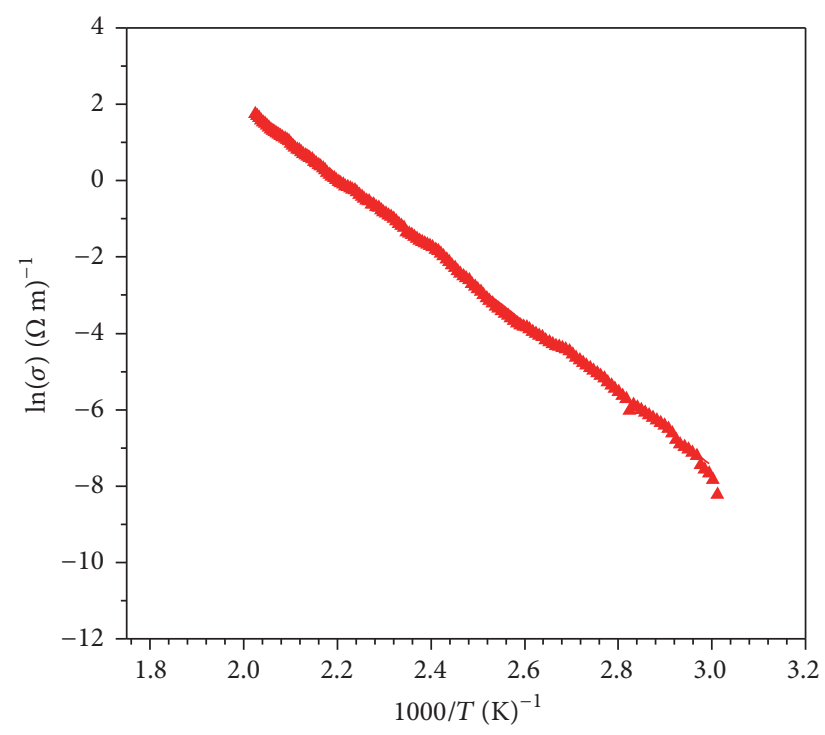

$\Delta 393 \mathrm{~K}$

(b)

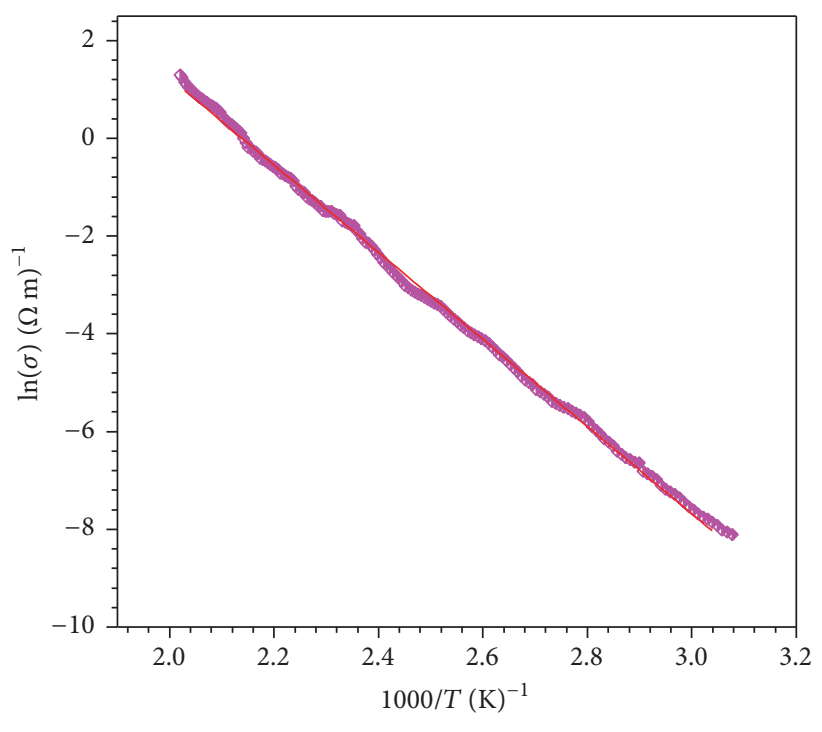

$\triangleleft 473 \mathrm{~K}$

FIGURE 14: Representation of $\ln (\sigma)$ as a function of $1 / T$ for $40 \mathrm{~nm}$ film thickness at different annealing temperature.

and lattice crystallinity affected by heat treated process of the films. Some nanoparticle aggregates appear by FESEM due to the exposed of thin film to high annealing temperature. Result of d.c. electrical conductivity for annealed $40 \mathrm{~nm}$ revealed an intrinsic conduction mechanism, and the calculated activation energy changed with heat treated temperature.

It could be concluded that the crystallinity of annealed $\mathrm{Sb}_{37.07} \mathrm{Mn}_{1.95} \mathrm{Se}_{60.98}$ nanocrystalline films was enhanced and the particle size increases as a result of both effects of increasing film thickness and annealing temperature. This is consequently reflected on their optical and electrical properties by decreasing their direct optical band gap, degree of disorder, and activation energy.

\section{Conflicts of Interest}

The authors declare that there are no conflicts of interest regarding the publication of this paper. 


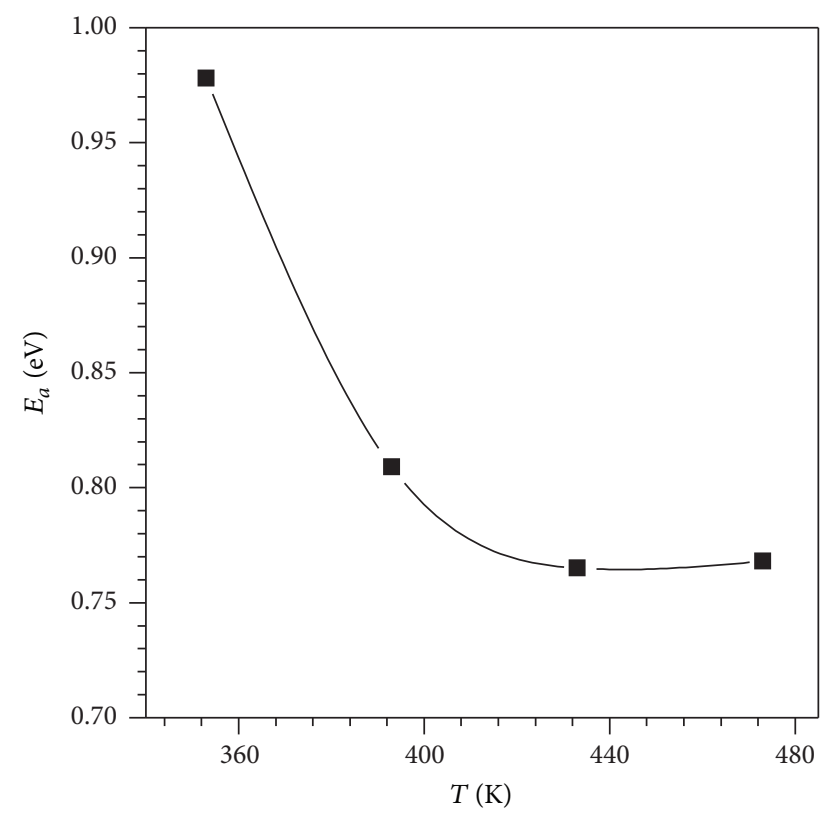

FIGURE 15: Variation of activation energy of $40 \mathrm{~nm}$ film thickness with annealing temperature.

\section{Acknowledgments}

This research was funded by National Research Centre, Cairo, Egypt, internal Project no. 10040206.

\section{References}

[1] Y. Hanifehpour, S. W. Joo, and B.-K. Min, " $\mathrm{Lu}^{3+} / \mathrm{Yb}^{3+}$ and $\mathrm{Lu}^{3+} / \mathrm{Er}^{3+}$ co-doped antimony selenide nanomaterials: synthesis, characterization, and electrical, thermoelectrical, and optical properties," Nanoscale Research Letters, vol. 8, no. 1, article 141, 2013.

[2] I. S. Virt, I. O. Rudyj, I. V. Kurilo et al., "Properties of $\mathrm{Sb}_{2} \mathrm{~S}_{3}$ and $\mathrm{Sb}_{2} \mathrm{Se}_{3}$ thin films obtained by pulsed laser ablation," Semiconductors, vol. 47, no. 7, pp. 1003-1007, 2013.

[3] Y. Zhou, L. Wang, S. Chen et al., "Thin-film $\mathrm{Sb}_{2} \mathrm{Se}_{3}$ photovoltaics with oriented one-dimensional ribbons and benign grain boundaries," Nature Photonics, vol. 9, no. 6, pp. 409-415, 2015.

[4] S. Messina, M. T. S. Nair, and P. K. Nair, "Antimony selenide absorber thin films in all-chemically deposited solar cells," Journal of the Electrochemical Society, vol. 156, no. 5, pp. H327H332, 2009.

[5] M. R. Filip, C. E. Patrick, and F. Giustino, "GW quasiparticle band structures of stibnite, antimonselite, bismuthinite, and guanajuatite," Physical Review B, vol. 87, no. 20, Article ID 205125, 2013.

[6] C. E. Patrick and F. Giustino, "Structural and electronic properties of semiconductor-sensitized solar-cell interfaces," Advanced Functional Materials, vol. 21, no. 24, pp. 4663-4667, 2011.

[7] X. Liu, J. Chen, M. Luo et al., "Thermal evaporation and characterization of $\mathrm{Sb}_{2} \mathrm{Se}_{3}$ thin film for substrate $\mathrm{Sb}_{2} \mathrm{Se}_{3} / \mathrm{CdS}$ solar cells," ACS Applied Materials \& Interfaces, vol. 6, no. 13, pp. 10687-10695, 2014.
[8] Y. Lai, Z. Chen, C. Han et al., "Preparation and characterization of $\mathrm{Sb}_{2} \mathrm{Se}_{3}$ thin films by electrodeposition and annealing treatment," Applied Surface Science, vol. 261, pp. 510-514, 2012.

[9] T. T. Ngo, S. Chavhan, I. Kosta, O. Miguel, H.-J. Grande, and R. Tena-Zaera, "Electrodeposition of antimony selenide thin films and application in semiconductor sensitized solar cells," ACS Applied Materials and Interfaces, vol. 6, no. 4, pp. 2836-2841, 2014.

[10] A. U. Bajpeyee, "Deposition and characterization of antimony selenide thin films," Multilogic in Science, vol. 2, pp. 38-43, 2012.

[11] J. Horák, P. Lošt'ák, Č. Drašar, J. S. Dyck, Z. Zhou, and C. Uher, "Defect structure of $\mathrm{Sb}_{2-x} \mathrm{Mn}_{x} \mathrm{Te}_{3}$ single crystals," Journal of Solid State Chemistry, vol. 178, no. 9, pp. 2907-2912, 2005.

[12] J. Choi, S. Choi, J. Choi et al., "Magnetic properties of Mn-doped $\mathrm{Bi}_{2} \mathrm{Te}_{3}$ and $\mathrm{Sb}_{2} \mathrm{Te}_{3}$," Physica Status Solidi (B) Basic Research, vol. 241, no. 7, pp. 1541-1544, 2004.

[13] J. Choi, H.-W. Lee, B.-S. Kim et al., "Mn-doped $\mathrm{V}_{2} \mathrm{VI}_{3}$ semiconductors: single crystal growth and magnetic properties," Journal of Applied Physics, vol. 97, no. 10, Article ID 10D324, 2005.

[14] J. S. Dyck, P. Švanda, P. Lošt’ák, J. Horák, W. Chen, and C. Uher, "Magnetic and transport properties of the $\mathrm{V}_{2}-\mathrm{VI}_{3}$ diluted magnetic semiconductor $\mathrm{Sb}_{2-x} \mathrm{Mn}_{x} \mathrm{Te}_{3}$," Journal of Applied Physics, vol. 94, no. 12, pp. 7631-7635, 2003.

[15] P. Janíček, Č. Drašar, P. Lošt'Ák, J. Vejpravová, and V. Sechovský, "Transport, magnetic, optical and thermodynamic properties of $\mathrm{Bi}_{2-x} \mathrm{Mn}_{x} \mathrm{Se}_{3}$ single crystals," Physica B: Condensed Matter, vol. 403, no. 19-20, pp. 3553-3558, 2008.

[16] K. W. Sun, C.-H. Yang, T.-Y. Ko, H.-W. Chang, and C.-W. Liu, "Spectroscopy of a single $\mathrm{Sb}_{2} \mathrm{Se}_{3}$ nanorod," Pure and Applied Chemistry, vol. 81, no. 8, pp. 1511-1522, 2009.

[17] J. Ma, Y. Wang, Y. Wang et al., "One-dimensional $\mathrm{Sb}_{2} \mathrm{Se}_{3}$ nanostructures: solvothermal synthesis, growth mechanism, optical and electrochemical properties," CrystEngComm, vol.13, no. 7, pp. 2369-2374, 2011.

[18] T. Y. Ko, C. H. Yang, K. W. Sun, H. W. Chang, B. Sarkar, and C. W. Liu, "Electrical and optical properties of a single $\mathrm{Sb}_{2} \mathrm{Se}_{3}$ nanorod," Central European Journal of Chemistry, vol. 7, no. 2, pp. 197-204, 2009.

[19] Y. Zhang, G. Li, B. Zhang, and L. Zhang, "Synthesis and characterization of hollow $\mathrm{Sb}_{2} \mathrm{Se}_{3}$ nanospheres," Materials Letters, vol. 58, no. 17-18, pp. 2279-2282, 2004.

[20] G.-Y. Chen, B. Dneg, G.-B. Cai et al., "The fractal splitting growth of $\mathrm{Sb}_{2} \mathrm{~S}_{3}$ and $\mathrm{Sb}_{2} \mathrm{Se}_{3}$ hierarchical nanostructures," Journal of Physical Chemistry C, vol. 112, no. 3, pp. 672-679, 2008.

[21] Q. Xie, Z. Liu, M. Shao, L. Kong, W. Yu, and Y. Qian, "Polymercontrolled growth of $\mathrm{Sb}_{2} \mathrm{Se}_{3}$ nanoribbons via a hydrothermal process," Journal of Crystal Growth, vol. 252, no. 4, pp. 570-574, 2003.

[22] J. Wang, Z. Deng, and Y. Li, "Synthesis and characterization of $\mathrm{Sb}_{2} \mathrm{Se}_{3}$ nanorods," Materials Research Bulletin, vol. 37, no. 3, pp. 495-502, 2002.

[23] G. Chen, W. Wang, C. Wang, T. Ding, and Q. Yang, "Controlled synthesis of ultrathin $\mathrm{Sb}_{2} \mathrm{Se}_{3}$ nanowires and application for flexible photodetectors," Advanced Science, vol. 2, no. 10, Article ID 1500109, 2015.

[24] Y.-Q. Liu, M. Zhang, F.-X. Wang, and G.-B. Pan, "Facile microwave-assisted synthesis of uniform $\mathrm{Sb}_{2} \mathrm{Se}_{3}$ nanowires for high performance photodetectors," Journal of Materials Chemistry C, vol. 2, no. 2, pp. 240-244, 2014.

[25] 2001 JCPDS-International Centre for Diffraction Data, Card number (15-0861). 
[26] Z. Li, H. Zhu, Y. Guo et al., "Efficiency enhancement of $\mathrm{Sb}_{2} \mathrm{Se}_{3}$ thin-film solar cells by the co-evaporation of $\mathrm{Se}$ and $\mathrm{Sb}_{2} \mathrm{Se}_{3}$," Applied Physics Express, vol. 9, no. 5, Article ID 052302, 2016.

[27] R. D. Shannon, "Revised effective ionic radii and systematic studies of interatomic distances in halides and chalcogenides," Acta Crystallographica Section A, vol. 32, pp. 751-767, 1976.

[28] M. A. Mahdy, I. K. El Zawawi, and E. A. El-Sayad, "Influence of temperature on the magnetic behavior of the $\mathrm{Sb}_{35.75} \mathrm{Mn}_{1.43} \mathrm{Se}_{2.82}$ compound," The European Physical Journal Plus, vol. 132, no. 2, article 81, 2017.

[29] B. D. Cullitty, Elements of X-Ray Diffraction, Addison-Wesley, Boston, Mass, USA, 2nd edition, 1978.

[30] S. Kumar, P. Yousaf Khan, N. K. Verma, and S. K. Chakarvarti, "Optical parameters of ZnSe chalcogenide nanostructures," Chalcogenide Letters, vol. 5, no. 7, pp. 143-152, 2008.

[31] J. I. Pankove, Optical Processes in Semiconductors, Prentice-Hall, Englewood Cliffs, NJ, USA, 1971.

[32] N. kumar, U. Parihar, R. Kumar, K. J. Patel, C. J. Panchal, and N. Padha, "Effect of film thickness on optical properties of tin selenide thin films prepared by thermal evaporation for photovoltaic applications," American Journal of Materials Science, vol. 2, no. 1, pp. 41-45, 2012.

[33] J. Tauc, "Optical properties of amorphous semiconductors," in Amorphous and Liquid Semiconductors, 220, chapter 4, p. 159, Plenum Press, London, UK, 1974.

[34] I. K. El Zawawi and M. A. Mahdy, "Synthesis and characterization of low particle size nanocrystalline SnSe thin films," Journal of Materials Science: Materials in Electronics, vol. 24, no. 6, pp. 2106-2111, 2013.

[35] J. Tauc, Amorphous and Liquid Semiconductors, Plenum, London, UK, 1974.

[36] A. M. Fernández and M. G. Merino, "Preparation and characterization of $\mathrm{Sb}_{2} \mathrm{Se}_{3}$ thin films prepared by electrodeposition for photovoltaic applications," Thin Solid Films, vol. 366, no. 1-2, pp. 202-206, 2000.

[37] K. Y. Rajpure, C. D. Lokhande, and C. H. Bhosale, "Effect of the substrate temperature on the properties of spray deposited SbSe thin films from non-aqueous medium," Thin Solid Films, vol. 311, no. 1-2, pp. 114-118, 1997.

[38] E. A. El-Sayad, B. S. Farag, and L. I. Soliman, "Effect of annealing temperature on the structural and optical properties of Sb-MnSe thin films," Journal of Physics D: Applied Physics, vol. 42, no. 22, Article ID 225401, 2009.

[39] B. Kuznetsov, Physical Principles of Microelectronics, Mir Publishers, 1974, English Translation.

[40] N. F. Mott and E. A. Davis, Electronic Process in Non-Crystalline Materials, Clarendon Press, Oxford, UK, 1979.

[41] F. Skuban, S. R. Lukić, D. M. Petrović, I. Savić, and Y. S. Tver'yanovich, "Optical gap and dc conductivity of disordered materials of (As2Se3) ${ }_{100-x}(\mathrm{SbSI})_{x}$ type," Journal of Optoelectronics and Advanced Materials, vol. 7, no. 4, pp. 1793-1799, 2005.

[42] E. A. El-Sayad, B. S. Farag, and A. T. Amin, "Electrical properties of crystalline $\mathrm{Pb}_{x} \mathrm{Sn}_{1-x} \mathrm{Te}_{0.5} \mathrm{Se}_{0.5}$ thin films," Vacuum, vol. 84, pp. 807-811, 2010. 

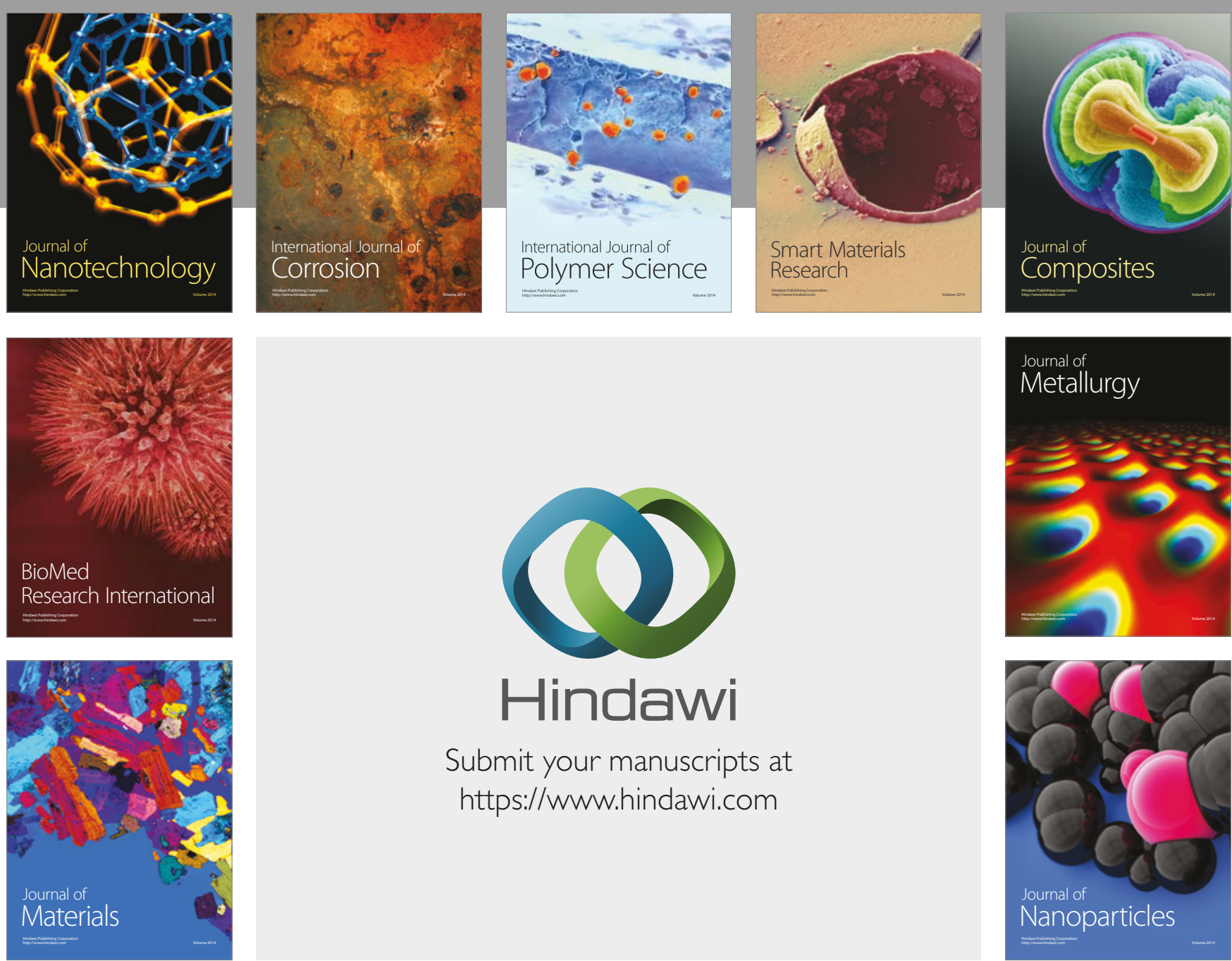

\section{Hindawi}

Submit your manuscripts at

https://www.hindawi.com
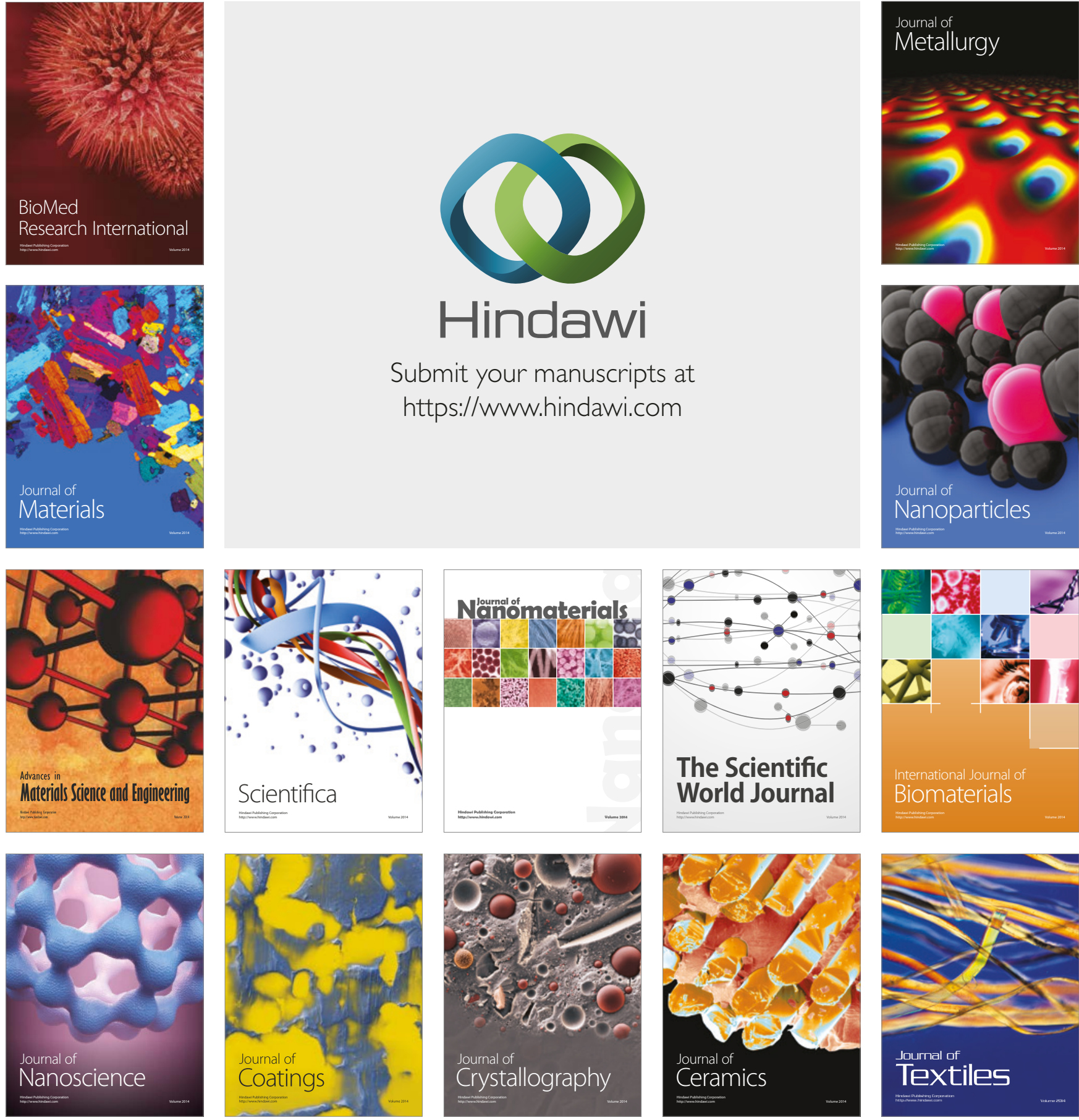

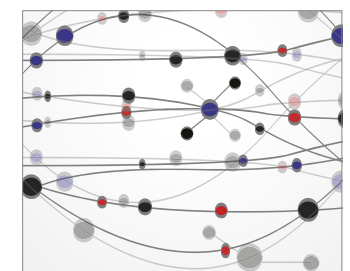

The Scientific World Journal
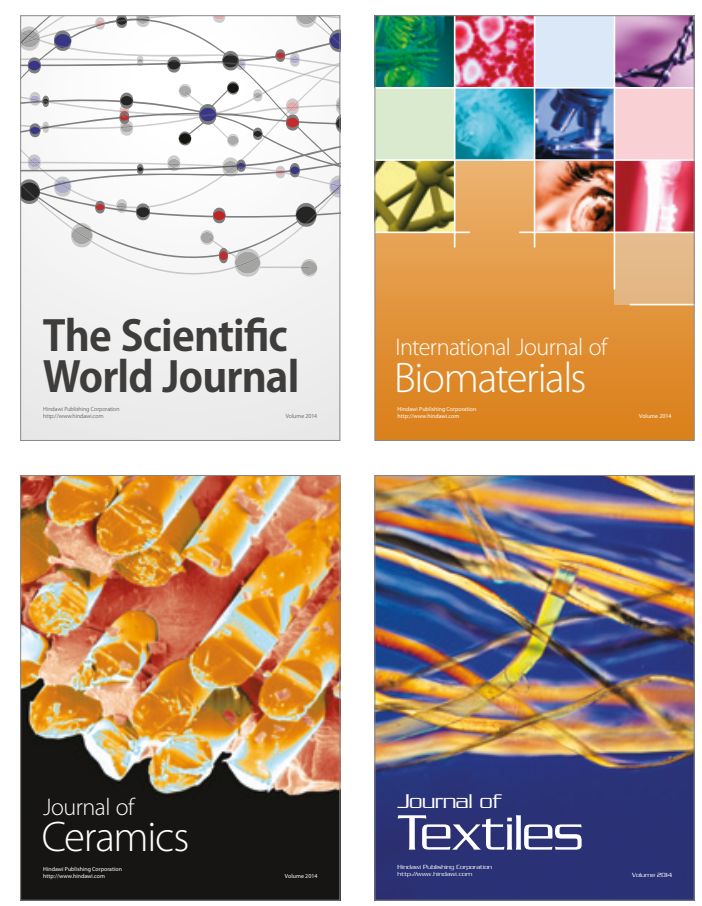